\title{
Predictability of Recurrent Weather Regimes over North America during Winter from Submonthly Reforecasts
}

\author{
N. VigAUd AND A.W. ROBERTSON \\ International Research Institute for Climate and Society, Earth Institute, Columbia University, New York, New York \\ M. K. TIPPETT \\ Department of Applied Physics and Applied Mathematics, Columbia University, New York, New York, and \\ Department of Meteorology, Center of Excellence for Climate Change Research, King Abdulaziz \\ University, Jiddah, Saudi Arabia
}

(Manuscript received 14 February 2018, in final form 5 June 2018)

\begin{abstract}
Four recurrent weather regimes are identified over North America from October to March through a $k$-means clustering applied to MERRA daily 500-hPa geopotential heights over the 1982-2014 period. Three regimes resemble Rossby wave train patterns with some baroclinicity, while one is related to an NAO-like meridional pressure gradient between eastern North America and western regions of the North Atlantic. All regimes are associated with distinct rainfall and surface temperature anomalies over North America. The four-cluster partition is well reproduced by ECMWF week-1 reforecasts over the 1995-2014 period in terms of spatial structures, daily regime occurrences, and seasonal regime counts. The skill in forecasting daily regime sequences and weekly regime counts is largely limited to 2 weeks. However, skill relationships with the MJO, ENSO, and SST variability in the Atlantic and Indian Oceans suggest further potential for subseasonal predictability based on wintertime large-scale weather regimes.
\end{abstract}

\section{Introduction}

The severity of recent extreme droughts and floods has lately increased the interest in their prediction at subseasonal-to-seasonal (S2S) time scales (2 weeks to a season ahead), owing to modeling advances (Vitart 2014) and a better understanding of climate phenomena at these time scales. Sources of predictability include the inertia of sea surface temperature (SST) anomalies and the MJO (Waliser et al. 2003; Waliser 2011; Neena et al. 2014), but also stratospheric processes, including the QBO (Baldwin and Dunkerton 2001; Scaife and Knight 2008; Yoo and Son 2016), memory in soil moisture (Koster et al. 2010), snow cover (Lin and Wu 2011), and sea ice (Holland et al. 2011).

The understanding of large-scale circulation or weather regimes (WRs), which appear repeatedly at fixed geographical locations and persist beyond the lifetimes of individual weather disturbances (i.e., beyond about a

\footnotetext{
Corresponding author: Nicolas Vigaud, nicolas.vigaud@gmail. com
}

week), is central to long-range forecasting (i.e., on time scales between a week and a season) since the theoretical limit of atmospheric deterministic predictability is also about 10-15 days (Ghil and Robertson 2002). For the Europe-North Atlantic sector, the four-regime wintertime classification of Vautard (1990) is still used as a reference and has recently been used to explain some ECMWF model biases related to blocking transitions and persistence (Ferranti et al. 2015). The use of weather regimes to express forecasts is, however, less common in North America than in Europe, despite previous studies demonstrating the advantages of weather typing over the United States (Robertson and Ghil 1999; Stan and Straus 2007; Riddle et al. 2013; Robertson et al. 2015). The North American continent and upstream Pacific are both much larger and complex, and hence, there is a need to improve our knowledge of the influence of WRs on North American climate and underlying physical processes and to assess their S2S predictability. The reduced-order WR view can help stratifying wintertime surface weather over North America following Ghil and Robertson (2002). Thus, the goal of this study is to 
examine these recurrent regimes and their reproducibility in submonthly reforecasts.

Large-scale teleconnection patterns (Bjerknes 1969) refer to geographically fixed modes of low-frequency variability, which, for the Northern Hemisphere wintertime, include the Pacific-North American pattern (PNA) and its reversed pattern alongside regionally blocked and zonal flows related to the North Atlantic Oscillation (NAO; Kimoto and Ghil 1993a,b). The NAO is the primary mode of atmospheric variability over the North Atlantic region, influencing significantly both European and North American climates. It has recently been argued to be predictable up to 1 year ahead (Eade et al. 2014; Scaife et al. 2014; Dunstone et al. 2016), an aspect that is disputed, as for instance, when considering decadal variations of the NAO (Weisheimer et al. 2017). During the positive NAO phase, the increased difference in pressure between the subpolar low and the subtropical high results in a strengthened jet stream at its mean latitude (Woollings et al. 2010; Madonna et al. 2017) and favors cold air outbreak over the western North Atlantic close to North America (Kolstad et al. 2009; Papritz and Grams 2018), while the opposite is true for the negative NAO phase (Wallace and Gutzler 1981; Papritz and Grams 2018). Both phases affect the strength and position of the jet in the Atlantic, which is also the case for the PNA pattern in the Pacific (Athanasiadis et al. 2010). The representation of these jet variability patterns in dynamical models is tightly linked to that of the tropical Pacific mean state (Delcambre et al. 2013), whose improved representation would translate into increased predictability of retractions and latitudinal shifts of the North Pacific jet exit region in winter, with potential for medium-range forecasting due to their persistence (Jaffe et al. 2011; Griffin and Martin 2017). In addition, there is evidence for linkages between North Pacific and North Atlantic regimes through Rossby wave propagation (Rivière and Drouard 2015; Michel and Rivière 2011).

At interannual time scales, the prevalence of the tropical Northern Hemispheric pattern (TNH; Barnston and Livezey 1987), concomitant with northwest-southeasttilted negative heights anomalies over the North Pacific (Robertson and Ghil 1999) and more southerly and zonal storm tracks (Monteverdi and Null 1998) in winter during El Niño, translates into significant precipitation anomalies over the western United States. La Niña episodes, however, are associated with an increased meridional flow and blocking activity in the eastern North Pacific midlatitudes, where the jet stream strength becomes highly variable, while the mean jet position is shifted to the northwestern United States/southwestern Canada, leading to increased storminess and precipitation over large portions of central North America and the opposite over southern states (Ropelewski and Halpert 1987; Halpert and Ropelewski 1992).

At intraseasonal time scales, North American winter climate is influenced by the MJO through modulations of the jet stream, leading to cold air outbreaks, extreme heat, and flood events over North America (Higgins and Shi 2000; Lin et al. 2005, 2009; Cassou 2008; Zhou et al. 2012; Riddle et al. 2013). During MJO phase 5, for instance, when convection is increased over the Maritime Continent (MC), the jet stream tends to be shifted northward, leading to fewer storms along the U.S. East Coast in winter (Becker et al. 2011), while the pineapple express transporting moisture from the tropical Pacific is strengthened and leads to increased snow over the Sierra Nevada (Zhang 2013). The extratropical precipitation response to tropical MJO forcing has been largely explained in terms of Rossby wave propagation (Hoskins and Karoly 1981; Karoly 1983; Hoskins and Ambrizzi 1993) and is maximum when the MJO-induced diabatic heating has a dipole structure between the eastern Indian Ocean and the western Pacific (Lin et al. 2005; Lin and Brunet 2018). MJOinduced Rossby wave trains also impact North American wintertime surface temperatures with a precursive signal up to 2 weeks' lead-in particular for phases 3 and 7, associated with warming in central/eastern and northeastern Canada, respectively - which can be predicted with substantial skill (Lin and Brunet 2009; Yao et al. 2011).

The present study aims to diagnose October-March North American regional atmospheric circulation variability through a cluster analysis of daily $500-\mathrm{hPa}$ geopotential heights. Recurrent weather regimes at intraseasonal scales are identified in reanalyses, as well as subseasonal reforecasts from the S2S database (World Meteorological Organization 2013), with a focus on their reproducibility and predictability. The low-dimensional WR subspace is expected to provide insight into the high-dimensional S2S reforecasts by effectively stratifying wintertime surface weather over North America. The method and data are presented in more detail in the next section. Results from the cluster analysis based on MERRA reanalyses are discussed in section 3 alongside rainfall and atmospheric circulation anomalies associated with each regime. Their reproducibility in ECMWF week-1 reforecasts is then examined, as well as relationships to the MJO and large-scale teleconnections. In section 4, the predictability of observed weather regime sequences is last diagnosed from ECMWF reforecasts at week-1 to week-4 leads. Discussion and conclusions are presented in section 5 . 


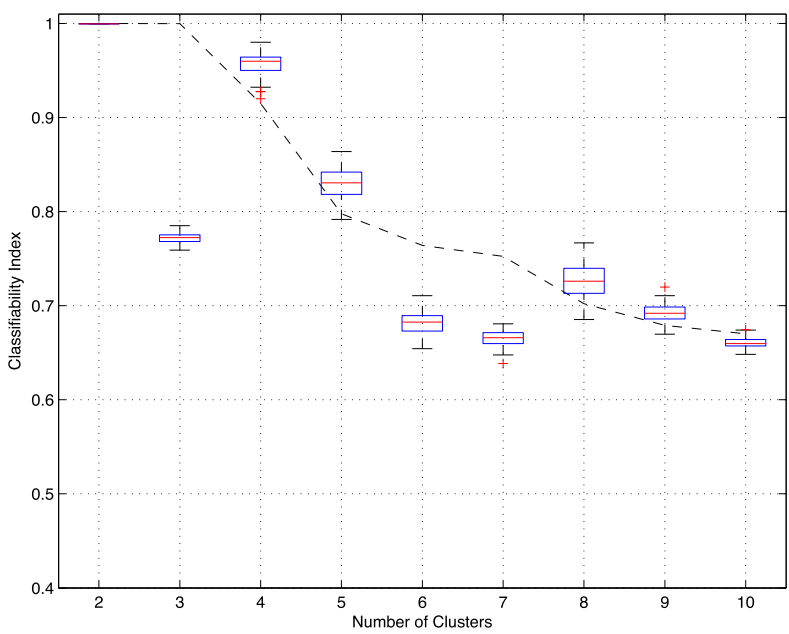

FIG. 1. Classifiability index as a function of the number of regimes $k$ (boxes). The $10 \%$ significance level (dashed line) is computed according to a first-order Markov process.

\section{Data and methods}

\section{a. Observation and forecast data}

Day-to-day variability in the atmospheric circulation over North America is examined in October-March (i.e., the extended winter season) using daily $500-\mathrm{hPa}$ geopotentials (Z500 in the following) from MERRA reanalyses version 1 , available on a $1 / 2^{\circ} \times 2 / 3^{\circ}$ grid from 1982 to 2014 (Liebmann and Smith 1996), while other MERRA fields are used to investigate atmospheric circulation features.

MERRA data are used to examine the impacts from each WR on rainfall and surface temperatures over North America, but this study also makes use of in situ precipitation estimates from the gauge-based unified precipitation developed by the National Oceanic and Atmospheric Administration (NOAA) and the National Centers for Environmental Predictions (NCEP) Climate Prediction Center (CPC) Unified Precipitation, which provides gridded daily values from 1980 to near present at $1 / 4^{\circ}$ spatial resolution (Chen et al. 2008).
The relationships between each WR and SSTs in the different oceanic basins are assessed using the NOAA Optimum Interpolation SST version 2 (OISST) dataset, consisting of daily values at $1 / 4^{\circ}$ (Reynolds et al. 2007), which were aggregated for October-March seasons from 1982 to 2014 .

To investigate the reproducibility of observed WRs by S2S models (section 3), daily Z500 fields from ECMWF week-1 (i.e., the period $[d, d+6]$ for a forecast issued on day $d$ ) 11-member reforecasts over the 1995-2014 period were obtained on a $1.5^{\circ} \times 1.5^{\circ}$ grid from the S2S database (Vitart et al. 2017) . In particular, the reforecasts belonging to all Monday real-time forecasts starting from October 2015 to March 2016 (i.e., 2 October-24 March start dates) were selected. This forecast period corresponds to version CY41R1 of the ECMWF monthly forecast system (Vitart 2014), which is run at $32-\mathrm{km}$ spatial resolution up to day 10 and $64 \mathrm{~km}$ after (i.e., Tco639/319 truncations). Submonthly regime predictability is then further examined using week-1 to week-4 reforecasts (i.e., periods from $[d, d+6]$ to $[d+21, d+27])$ in section 4 .

\section{b. Dynamical clustering approach}

Daily MERRA Z500 anomaly maps for the OctoberMarch season are first obtained by subtracting, on a daily basis and at each grid point, the daily mean 19822014 annual cycle smoothed using a 10-day running mean. To reduce the dimensionality of the problem and to ensure linear independence between input variables, an EOF analysis is first performed on the data correlation matrix prior to clustering. Even though the Z500 data were not filtered in time prior to the analysis, only a subset of the PCAs are retained in the following, which filters out the smallest, most transient spatiotemporal scales. In the case of MERRA, the first 12 PCs explaining $80.2 \%$ of the variance are retained. A partitioning into $k$ clusters is done through $k$-means (Michelangeli et al. 1995; Vigaud and Robertson 2017), which is based on the following two steps: 1) each datum is assigned to the cluster with the nearest mean using Euclidean distances (i.e., minimum sum of

TABLE 1. Contingency tables among the four daily 500-hPa geopotential classes from MERRA over the 1982-2014 period. The respective transition probabilities (\%), obtained by dividing separate class counts by the sum of the columns of each row, are indicated in parentheses. Asterisks (*) indicate significance at $0.1 \%$ level of $\chi^{2}$ test.

\begin{tabular}{|c|c|c|c|c|c|}
\hline Fromlto & Class 1 & Class 2 & Class 3 & Class 4 & Total \\
\hline Class 1 & $1094 *(77)$ & $57(4)$ & 148 (10) & $127(9)$ & $1426(22)$ \\
\hline Class 2 & $110(8)$ & $1104 *(76)$ & $109(7)$ & $124(9)$ & $1447(23)$ \\
\hline Class 3 & $74(5)$ & $162(11)$ & $1118 *(76)$ & $109(8)$ & $1463(23)$ \\
\hline Class 4 & $144(7)$ & $123(6)$ & 79 (4) & $1670 *(83)$ & 2016 (32) \\
\hline
\end{tabular}


a) MERRA CLASS1

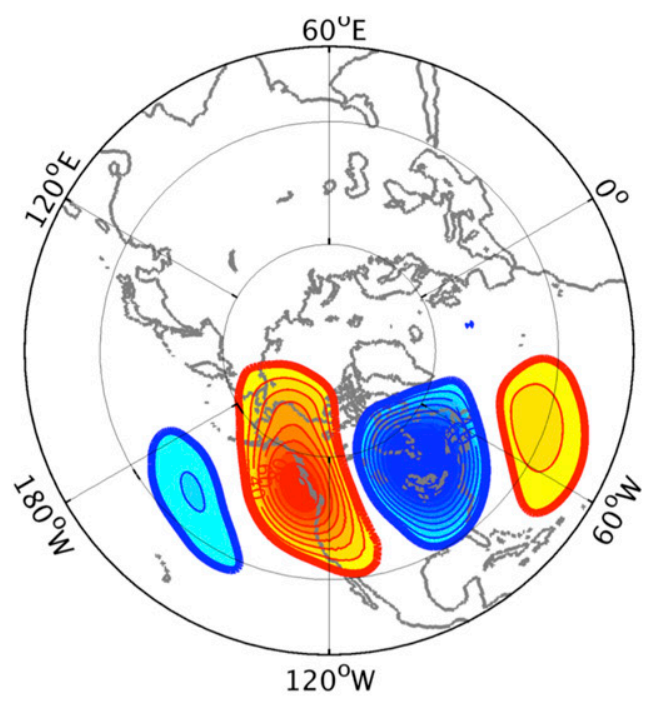

c) MERRA CLASS3

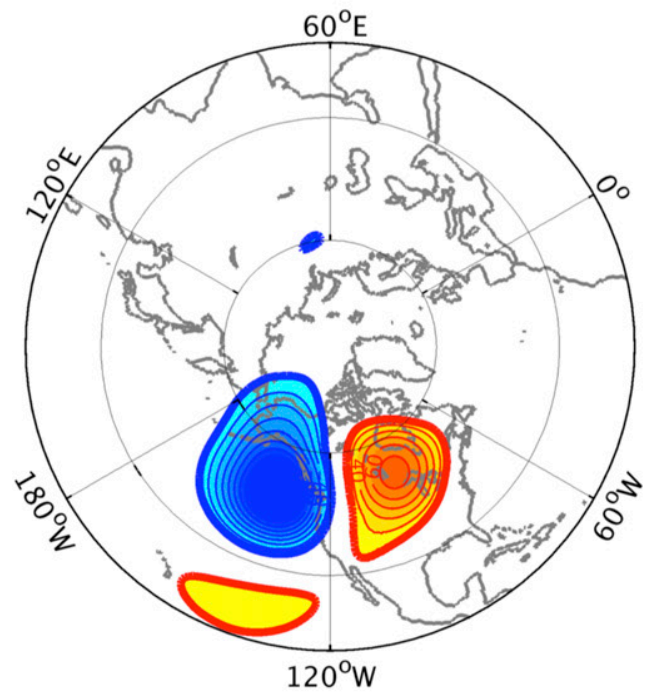

b) MERRA CLASS2

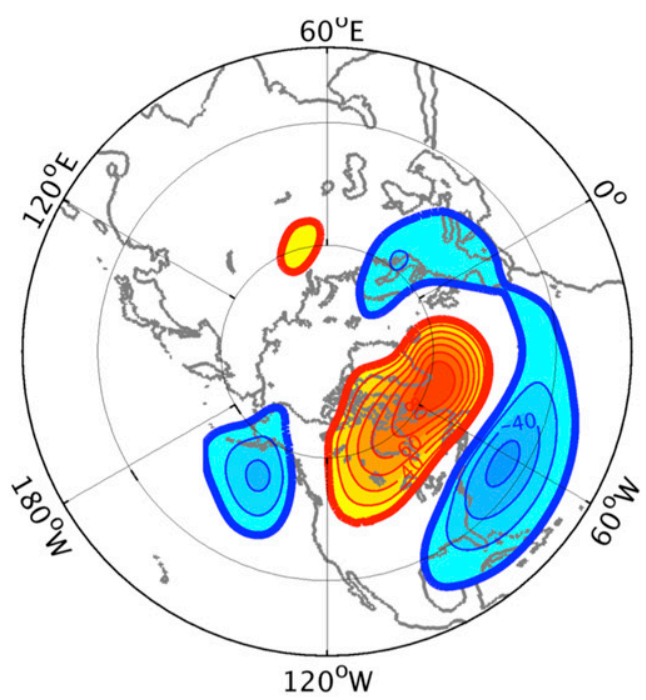

d) MERRA CLASS4

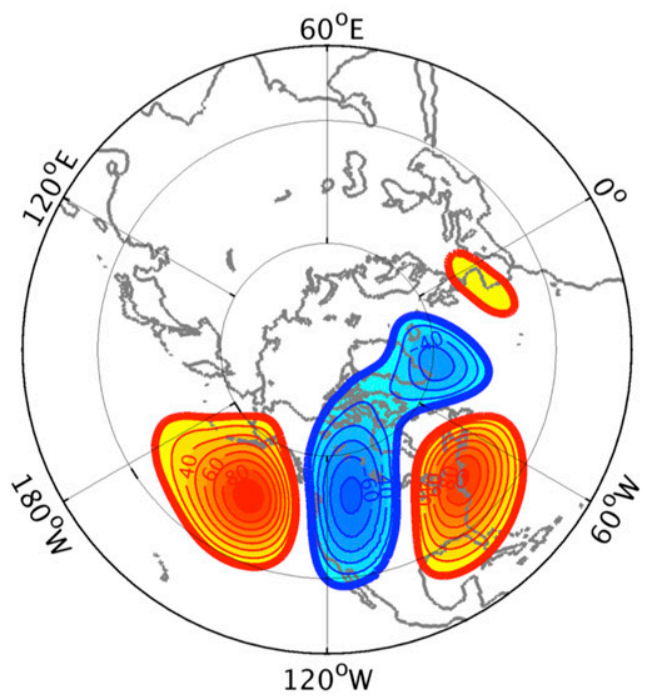

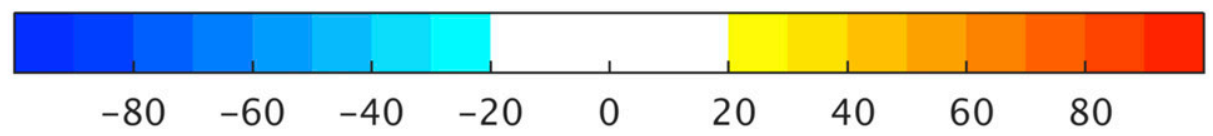

FIG. 2. Mean 1982-2014 October-March daily MERRA Z500 anomalies (m) for each regime. All anomalies are significant at 5\% level of Student's $t$ test.

the squared distances), then 2) the new means to be the centroids of the data in the new clusters are computed; both steps are repeated until convergence. The same methodology is applied to ECMWF week-1 daily Z500 fields aggregated from weekly starts issued in October-March over the 1995-2014 period. The Euclidean distance is then used to measure similarities between daily Z500 patterns and a given regime. The robustness of regime partitions is measured by a classifiability index (Michelangeli et al. 1995) and compared to confidence limits from a red-noise test (applied to Markov-generated red-noise data) following previous studies (Michelangeli et al. 1995; Moron and Plaut 2003; Vigaud et al. 2012; Vigaud and 
a)CLASS1

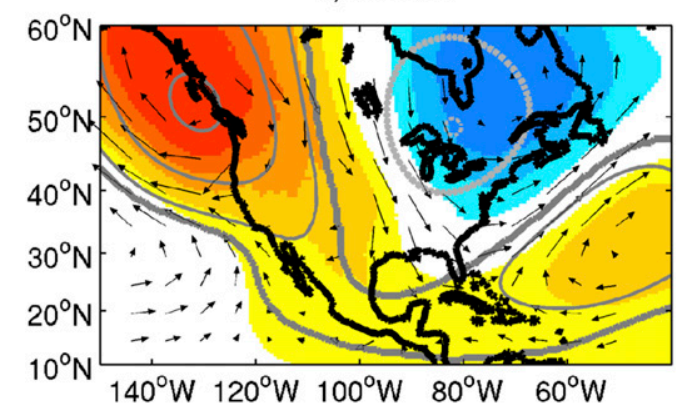

c) CLASS3

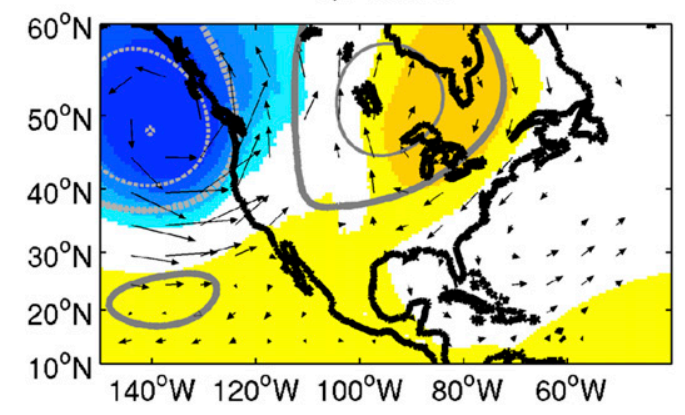

b)CLASS2

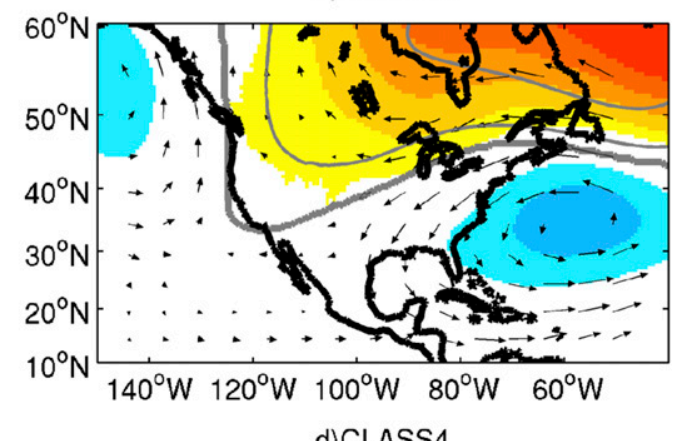

d) CLASS 4

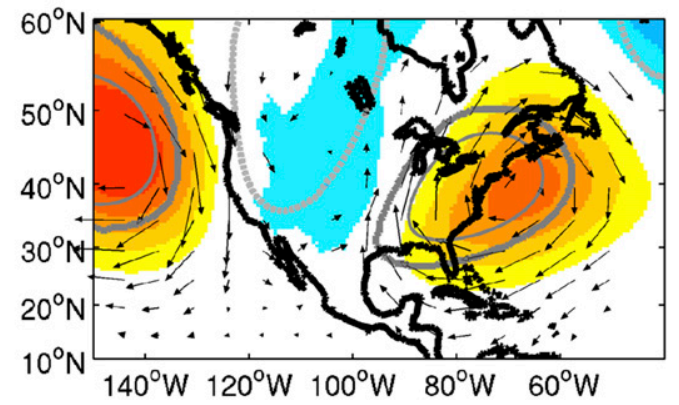

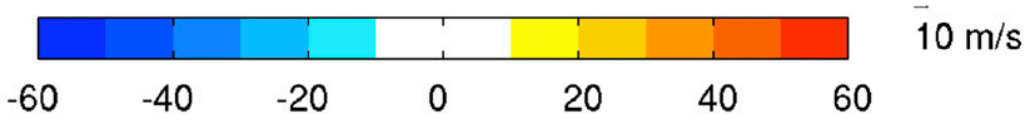

FIG. 3. Mean MERRA 200-hPa geopotentials (contours every $30 \mathrm{~m}$ ) alongside 850-hPa geopotentials (shadings; $\mathrm{m}$ ) and winds anomalies (vectors; $\mathrm{m} \mathrm{s}^{-1}$ ) for each regime in October-March over the 1982-2014 period. All anomalies are significant at $5 \%$ level of Student's $t$ test (for winds, at least one component).

Robertson 2017). Different domains of analysis were tested, ranging from a large domain that includes most of the North Pacific and Atlantic basins $\left(10^{\circ}-70^{\circ} \mathrm{N}\right.$, $150^{\circ} \mathrm{E}-20^{\circ} \mathrm{W}$ ) to a smaller domain limited to $10^{\circ}-70^{\circ} \mathrm{N}$, $150^{\circ}-40^{\circ} \mathrm{W}$. While both domains lead to comparable observed WR Z500 patterns, with pattern correlations about $0.77,0.67,0.81$, and 0.66 for the respective four regimes described in the following, those obtained from the small domain exhibit stronger associations with MERRA and CPC Unified precipitation over the United States. The sensitivity to the latitudinal bounds was also tested using a domain extending from the equator to $80^{\circ} \mathrm{N}$ for the same longitudes as the smaller domain $\left(150^{\circ}-40^{\circ} \mathrm{W}\right)$, which led also to similar patterns for regimes 1-4 correlated at $0.54,0.90,0.74$, and 0.50 with those obtained for the smaller domain. For these reasons, the smaller domain offers the most compact solution and is thus used in the following analysis. The clusterings of daily MERRA Z500 fields for the DJF and NDJFM periods both lead to similar anomalous patterns for each regime (not shown) significantly correlated (above 0.95 ) to those identified in
October-March, hence confirming their robustness to the exact definition of the season.

\section{c. Significance testing}

Composites and correlations in sections $3 \mathrm{a}$ and $3 \mathrm{c}$ are tested for statistical significance with two-tailed Student's $t$ tests and Monte Carlo simulations, respectively. Monte Carlo simulations are also used in section $3 b$ to test the significance of WR 1-4 counts during the eight MJO phases based on 1000 permutations of the MERRA daily sequences of the WRs, from which the 95th-percentile counts are computed.

Anomaly correlation coefficient (ACC) and root-meansquare error (RMSE) in section $4 \mathrm{~b}$ are, respectively, tested for significance with Monte Carlo simulations and a sign test (DelSole and Tippett 2016) by counting the number of times that reforecasts have more skill than climatology.

\section{d. Skill metrics}

In section 4, the skill of ECMWF reforecasts at week-1 to week-4 leads is examined in the WR subspace by 
a) ECMWF CLASS1

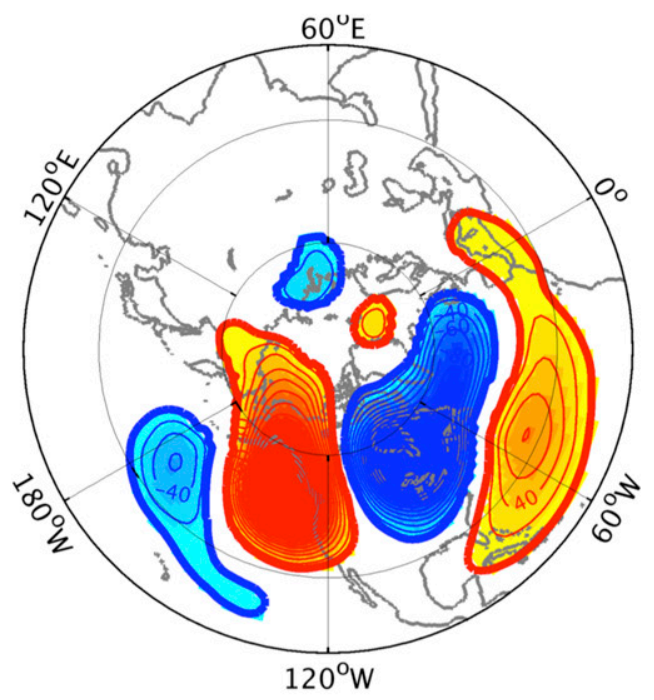

c) ECMWF CLASS3

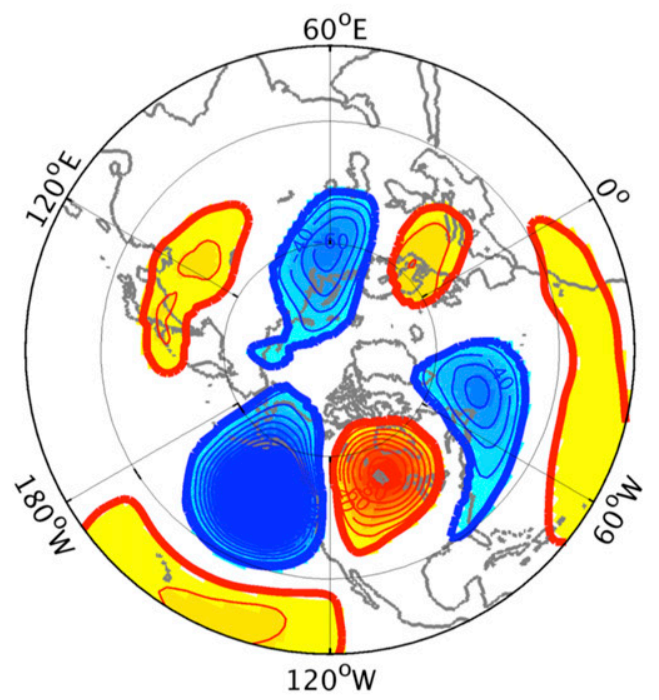

b) ECMWF CLASS2

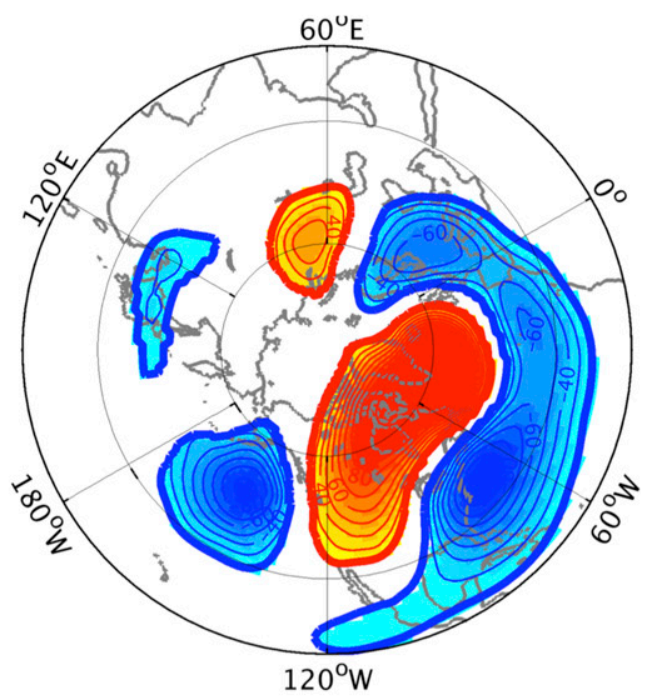

d) ECMWF CLASS4

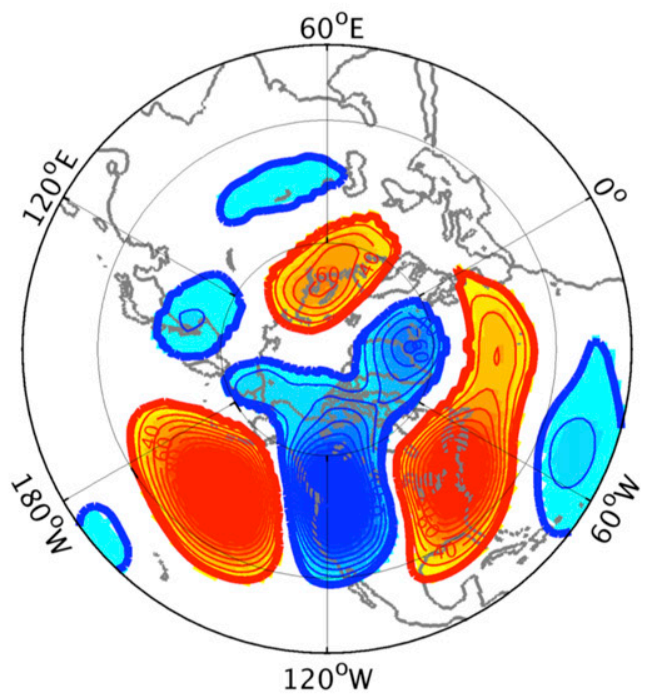

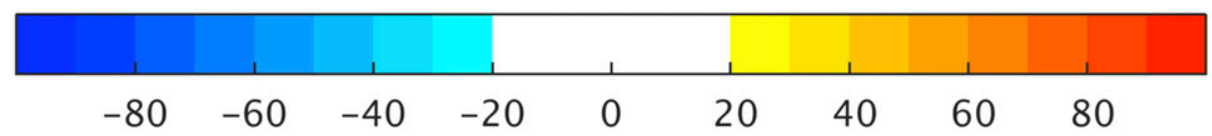

FIG. 4. Mean 1995-2014 October-March ECMWF week-1 anomalies (m) for each regime. All anomalies are significant at $5 \%$ level of Student's $t$ test.

projecting daily Z500 ensemble mean reforecasts onto the four MERRA regime patterns. Skill is first diagnosed at daily time scale and for all regimes by computing the multiple-category Gerrity skill score (Gerrity 1992) from the $4 \times 4$ contingency table formed by counts of daily WR occurrences (i.e., similar to Table 1), which provides a measure of forecast accuracy in predicting the correct category on each day relative to that of random chance. The counts for each daily lead are then aggregated for each weekly lead over the whole period.

In section $4 \mathrm{~b}$, the predictability of weekly regime occurrences is measured with ACC and RMSE between counts forecast in ECMWF and those observed in MERRA. 

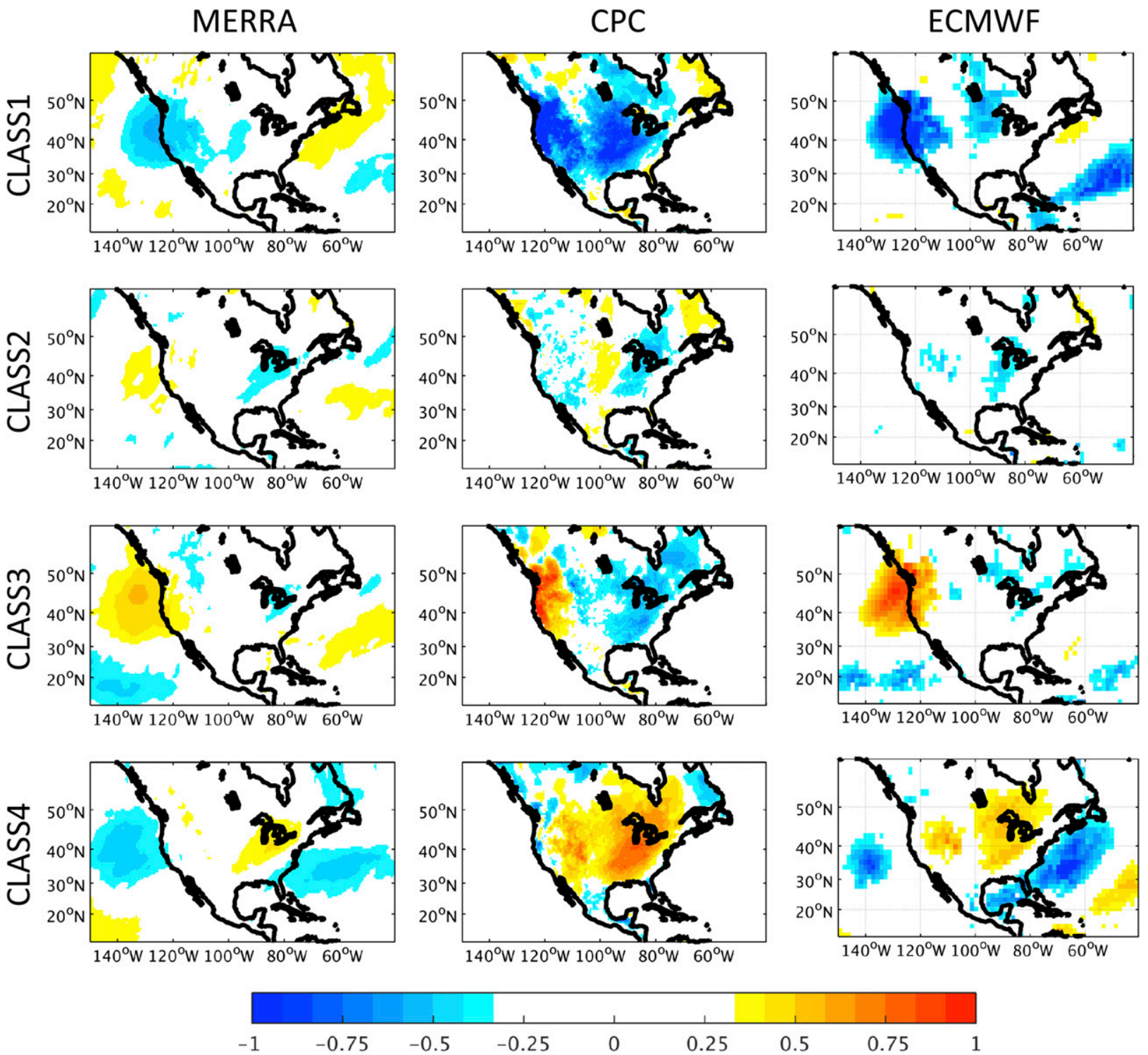

FIG. 5. Mean (left) MERRA and (middle) CPC Unified rainfall anomalies ( $\mathrm{mm} \mathrm{day}^{-1}$ ) for each regime during the October-March period identified from MERRA reanalyses over the 1982-2014 period and (right) ECMWF week-1 rainfall anomalies for each of the four regimes identified in ECMWF week 1 over the 1995-2014 period. All anomalies are significant at 5\% level of Student's $t$ test.

\section{Observed weather regimes}

Applying a $k$-means clustering to daily Z500 fields from MERRA over the small domain $\left(10^{\circ}-70^{\circ} \mathrm{N}, 150^{\circ}-40^{\circ} \mathrm{W}\right)$ leads to the classifiability index shown in Fig. 1, which exhibits a significant peak for $k=4$ and larger values. The four-cluster partition is the most compact and highly significant solution, thus selected for further analysis.

\section{a. Composite circulation patterns, rainfall, and surface temperature anomalies}

Figures $2 \mathrm{a}-\mathrm{d}$ display hemispheric maps of each regime's daily Z500 anomalies with respect to the mean seasonal cycle, constructed by compositing over all days assigned to each cluster. Overall, this four-regime partition agrees with the earlier classifications of Straus and Molteni (2004), Straus et al. (2007), and Stan and Straus (2007) based on daily Z200 reanalyses. Regime 1 is similar to the Alaskan ridge (AR), regime 3 to the Pacific trough (PT), and regime 4 to the Arctic low (AL) of Straus et al. (2007, see their Fig. 1). These three regimes consist of meridionally oriented ridge and trough anomalies (Figs. 2a,c,d) resembling Rossby wave trains; they have an approximate zonal wavenumber of 5-6 (Robertson and Metz 1989) and have similar structures 

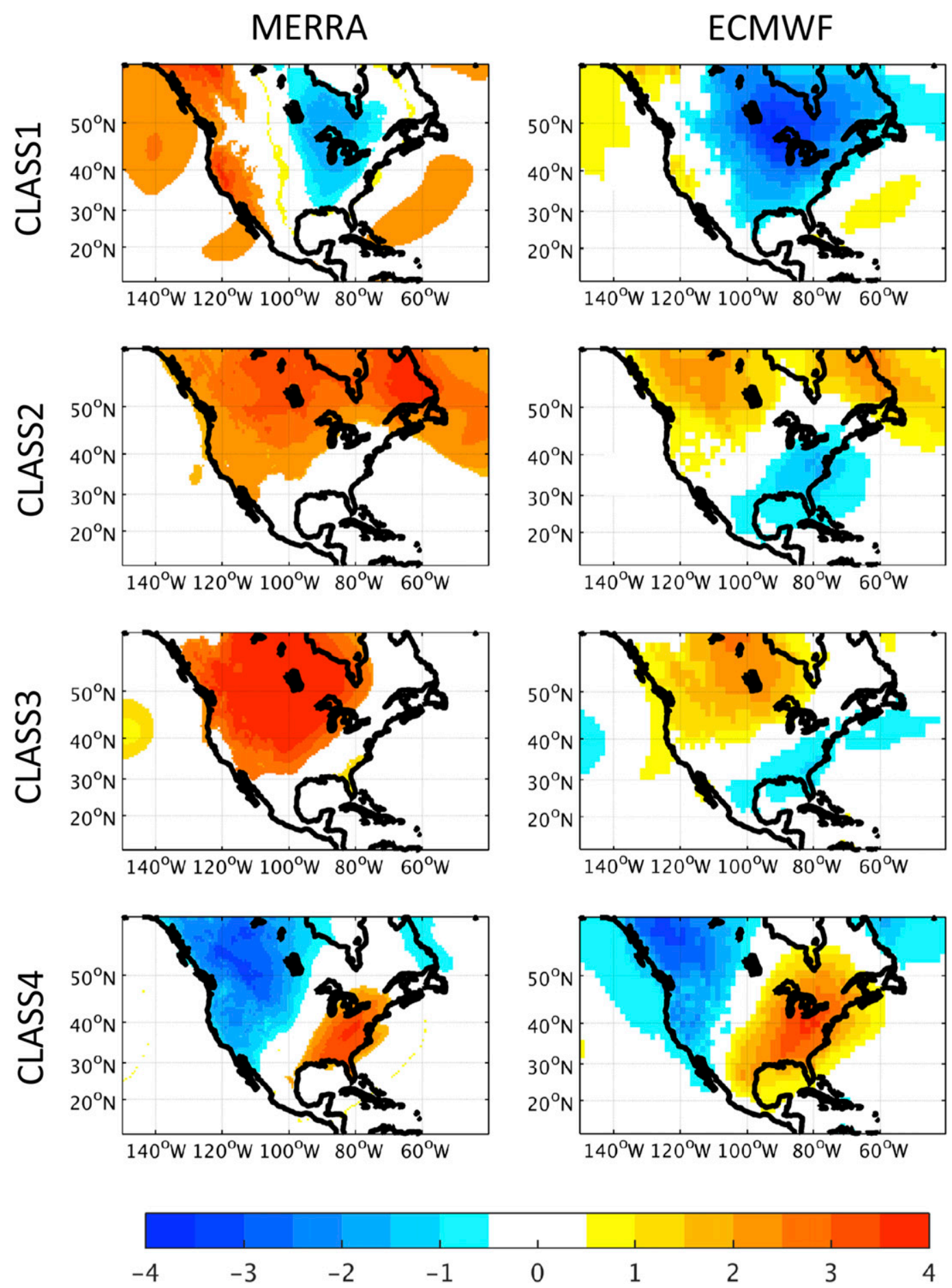

FIG. 6. Mean (left) MERRA 2-m temperature anomalies (K) for each regime during the October-March period identified from MERRA reanalyses over the 1982-2014 period and (right) those from ECMWF week 1 (K) for each of the four regimes identified in ECMWF week 1 over the 1995-2014 period. All anomalies are significant at 5\% level of Student's $t$ test. 
to the intermediate 10-30-day time scale waves identified by Blackmon et al. (1984). Regime 2 resembles the Arctic high (AH) of Straus et al. (2007), which, by contrast, is associated with a strong meridional pressure gradient between eastern North America and western regions of the North Atlantic, coinciding with zonally elongated ridging anomalies and low pressures to the north and south of about $35^{\circ} \mathrm{N}$, respectively (Fig. 2b). Geopotential composites at upper- and lower-tropospheric levels (Figs. 3a-d) reflect largely equivalent barotropic vertical structures, although some baroclinic westward tilt with height is seen in the wave train regimes, consistent with their intermediate-scale wavelengths (Blackmon et al. 1984). Notably, Z500 anomalies for regimes 1 and 4 bear similarities to the PNA teleconnection pattern that is related to large precipitation contrasts over the western United States and is associated with storm track shifts (Robertson and Ghil 1999). Those for regimes 2 and 3 are similar to the tropical North Hemispheric pattern known to prevail and impact western U.S. rainfall during El Niño episodes (Barnston and Livezey 1987; Robertson and Ghil 1999). Regime 2 also resembles the negative phase of the NAO, whose regionally blocked and zonal flows translate into local precipitation anomalies (Barnston and Livezey 1987; van den Dool et al. 2000; Chen and van den Dool 2003), while regime 4 bears some similarities to its positive phase. The four regimes are related to the well-known NAO and PNA teleconnection patterns, with pattern correlations of $0.10,-0.63,0.04$, and 0.40 with the NAO and $0.19,0.32,0.22$, and -0.60 with the PNA, computed using daily $500-\mathrm{hPa}$ geopotential heights. In particular, regime 2 resembles the negative phase of the NAO (Barnston and Livezey 1987), while regime 4 bears some similarities to its positive phase. Regime 4 also closely resembles the negative phase of the PNA pattern. In addition, maximum anomalies for regimes 2 and 4 over the North Atlantic correspond well with primary modes of variability in the mean position of the jet over the basin [i.e., $\mathrm{PC} 1$ and $\mathrm{PC} 2$ in Fig. 3 from Athanasiadis et al. (2010)], while the patterns of regimes 1 and 3 also resemble those in the North Pacific (PC2 and PC1 in their Fig. 4).

ECMWF week-1 ensemble mean reforecasts (i.e., forecast leads of 1-7 days) are next used as a baseline for assessing the performance of the S2S model's forecasts against these four observed regimes by analyzing all the October-March weekly reforecast starts over the 19952014 period. The ensemble mean represents the best estimate of the model's response to the information contained in the initial conditions. When preprocessing daily ECMWF Z500 anomalies from ECMWF week-1 reforecasts, 13 PCs explain about $80 \%$ of the variance of the 11-member ensemble mean reforecasts for the domain $\left(10^{\circ}-70^{\circ} \mathrm{N}, 150^{\circ}-40^{\circ} \mathrm{W}\right)$, compared to $12 \mathrm{PCs}$
TABLE 2. Contingency tables among the four daily 500-hPa geopotential classes from ECMWF week-1 reforecasts over the 1995-2014 period. The respective transition probabilities (\%), obtained by dividing separate class counts by the sum of the columns of each row, are indicated in parentheses. Asterisks $(*)$ indicate significance at $0.1 \%$ level of $\chi^{2}$ test.

\begin{tabular}{lcrrrr}
\hline \hline From $\backslash$ to & Class 1 & Class 2 & Class 3 & Class 4 & Total \\
\hline Class 1 & $322 *(75)$ & $31(7)$ & $45(10)$ & $34(8)$ & $432(23)$ \\
Class 2 & $44(10)$ & $319 *(71)$ & $51(11)$ & $36(8)$ & $450(25)$ \\
Class 3 & $25(5)$ & $50(10)$ & $372 *(75)$ & $48(10)$ & $495(27)$ \\
Class 4 & $40(9)$ & $49(11)$ & $29(16)$ & $342 *(74)$ & $460(25)$ \\
\hline
\end{tabular}

retained for the same variance fraction from MERRA. ECMWF Z500 anomalies were constructed by subtracting the week-1 averaged reforecast 1995-2014 climatology for each respective start week. The model's four regimes' Z500 anomalies, shown in Figs. 4a-d, have very similar spatial structures to those obtained from MERRA. Spatial pattern correlations between ECMWF week-1 and MERRA for regimes 1-4 are 0.94, $0.94,0.98$, and 0.85 when computed over the respective 1995-2014 and 1982-2014 periods. The anomalous patterns obtained for a bigger domain (not shown) are also almost identical and further illustrate the robustness of a four-cluster partition to including more or less of the Pacific basin. Anomalies are, however, more pronounced than those from reanalyses or when computed from a single ECMWF member, which yields amplitude very close to the reanalyses (not shown). For regime 3, for instance, ECMWF ensemble mean ridge and trough anomalies over the western and eastern United States are, respectively, 40-60 m higher in magnitude, with more significant relationships with the tropical Pacific (Fig. 4c) than those for reanalyses (Fig. 2c) or a single model member (not shown), suggesting that beyond being the best estimate of the model's forecast, the ensemble mean also provides a more robust representation of large-scale teleconnection patterns in the model. The very close correspondence between the MERRA and ECMWF week-1 reforecast WRs is evidence of the accuracy of the model's deterministic forecasts in the 1-7-day range.

Figure 5 displays the precipitation anomalies associated with each MERRA regime (left column) and CPC Unified Precipitation estimates (middle column). The CPC anomalies are much stronger, but with similar overall spatial structures for most regimes and close local correspondence between the polarity of the ridge/ trough anomalies and those of rainfall over both land and ocean.

Rainfall anomalies computed from ECMWF week-1 reforecasts (Fig. 5, right column) are similar in structure 
a) MERRA CLASS1

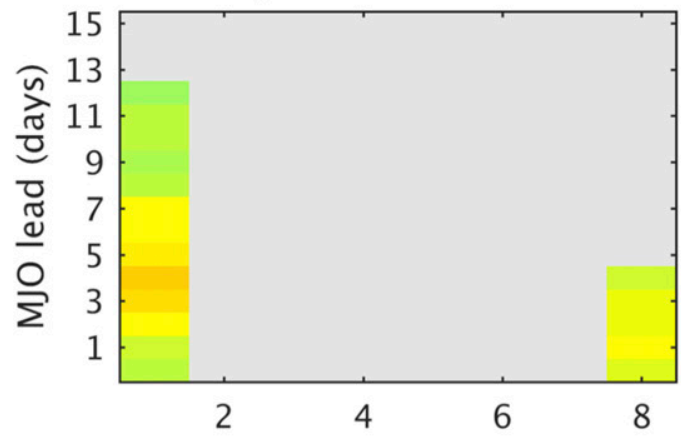

c) MERRA CLASS3

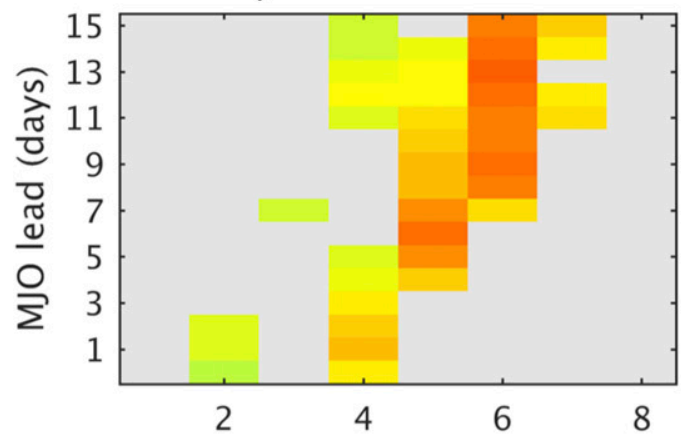

e) MERRA classes (Lead 0)

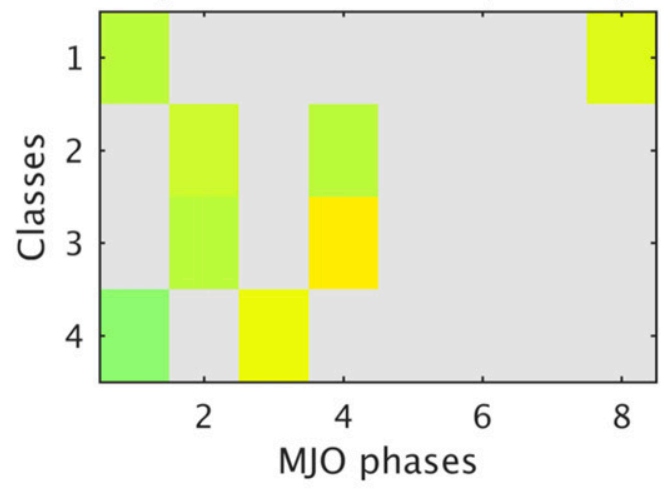

b) MERRA CLASS2

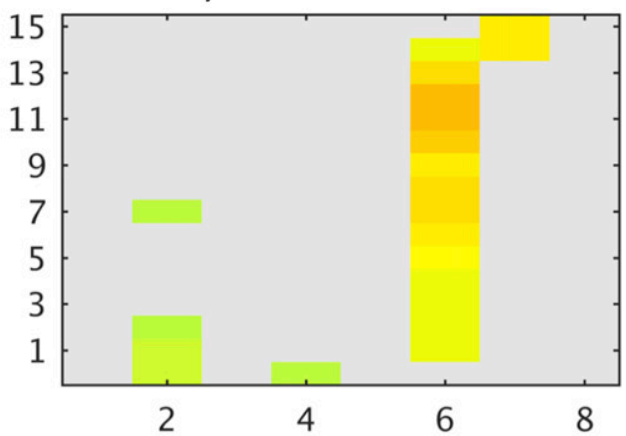

d) MERRA CLASS4

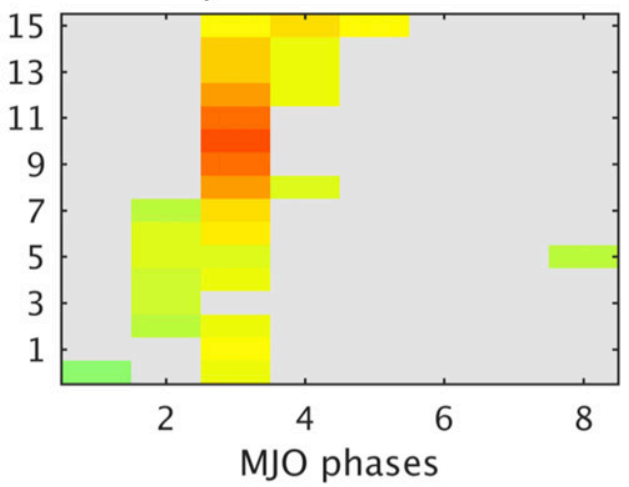

to those obtained for MERRA regimes, with higher magnitude than MERRA rainfall composites but lesser than those from CPC, suggesting potentially greater skill for ECMWF ensemble mean than reanalyses in regard to rainfall anomalies. For short forecast leads (days 1-7), the model is able to reproduce spatial structures of observed circulation types and their qualitative relationships with U.S. rainfall, thus suggesting potential rainfall predictability if regime evolution and transitions can be predicted.

Similar composite maps for surface temperatures are plotted in Fig. 6. The surface temperature signatures of 
a) CLASS1 (0.91)

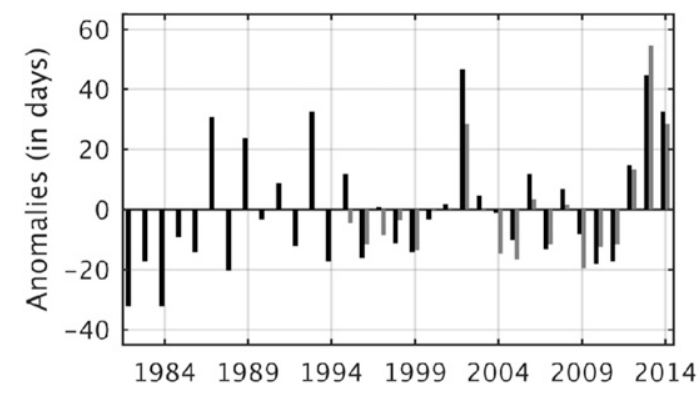

c) CLASS3 (0.95)

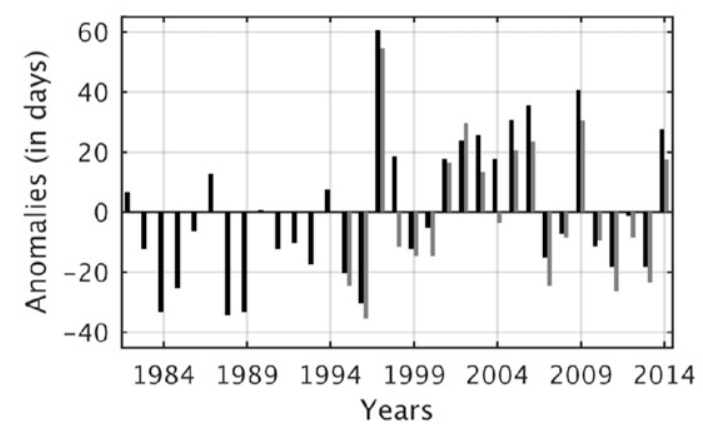

b) CLASS2 (0.84)

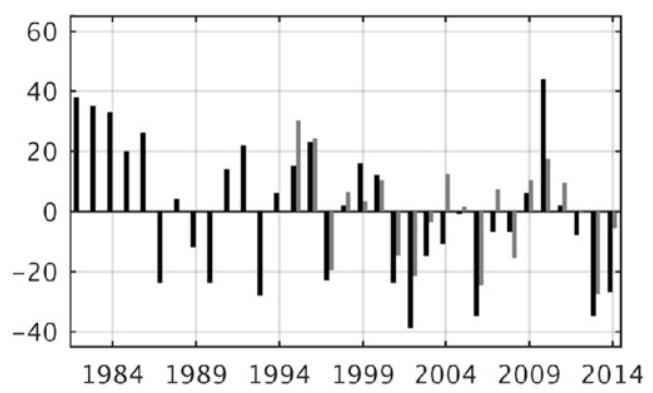

d) CLASS4 (0.89)

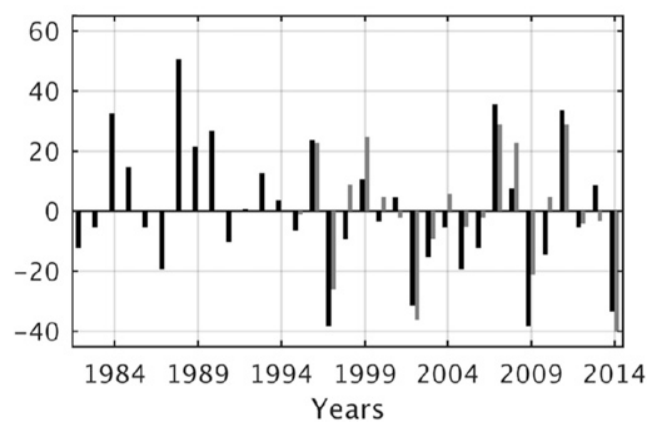

FIG. 8. Yearly regime occurrence anomalies for MERRA (black) and ECMWF week 1 (gray) per OctoberMarch seasons during the 1982-2014 and 1995-2014 periods, respectively. Correlations between both time series over the 1995-2014 period are indicated in the title of each panel and are all significant at $1 \%$ significance level using Monte Carlo simulations.

the four regimes are large scale, with warm and cold anomalies underlying anomalous Z500 geopotential height ridges and troughs, respectively, consistent with equivalent barotropic vertical structure. The spatial structures in MERRA and ECMWF are similar, although the warm anomalies are less pronounced in the reforecasts, which could also be due to the different periods used.

\section{b. Frequencies of occurrences and MJO phases}

Tables 1 and 2 show regime transitions for MERRA and ECMWF data, respectively, obtained by counting, for each day and each regime, the regime occurring the following day. The highest counts are found along the diagonal for both MERRA and ECMWF and reflect strong regime persistence at daily time scale. Regime persistence probabilities between reanalyses and model are similar, although somewhat underestimated for regime 4 in ECMWF week-1 reforecasts. The transition probabilities between different regimes (off-diagonal counts) are insignificant, compared to chance, between the different regimes and indicate that different regimes tend to be unrelated to each other, contrasting with Euro-Atlantic wintertime regimes, which tend to occur in transition cycles. Compared to MERRA, ECMWF simulates regimes $1-3$ more frequently and regime 4 less frequently. The mean persistence values of regimes 1-4 are very similar between the model and reanalyses; they are about 4 (4), 8 (8), 12 (13), and 19 (17) days in MERRA over the 1982-2015 (1995-2015) period and 4, 7, 11, and 16 days in ECMWF week 1 over 1995-2015.

To examine the observed relationships between each regime and the MJO, the frequency of occurrences of the four regimes is broken down by MJO phases for MERRA in Fig. 7. At 10-15-day lag, the frequencies of regimes 2-3 and 4 are substantially modulated and highest after MJO phases 6 and 3, respectively. Phases 3 and 6 of the MJO are characterized by strong dipolar anomalies in tropical diabatic heating with convection anomaly centers of opposite sign in the eastern Indian Ocean and the western Pacific; this dipole is known to be associated with an anomalous Rossby wave train extending into the North Pacific and North American region and favoring teleconnections in the extratropics (Lin et al. 2009, 2010; Lin and Brunet 2018). Regimes 2 and 3 have a trough over the North Pacific consistent with enhanced convection over the Indian Ocean (MJO phase 3), while the North Pacific ridge in regime 4 corresponds to MJO phase 6 with convection increased over the western Pacific. The 10-15-day time lag reflects the full 
a) CLASS1 SST

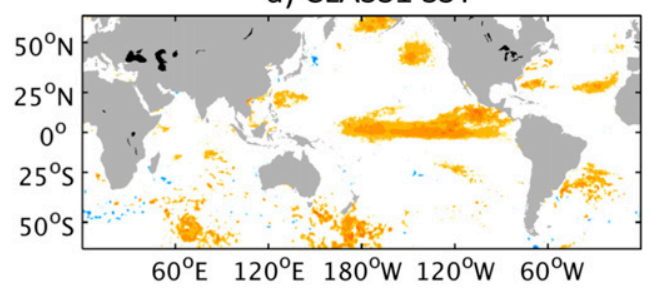

c) CLASS3 SST

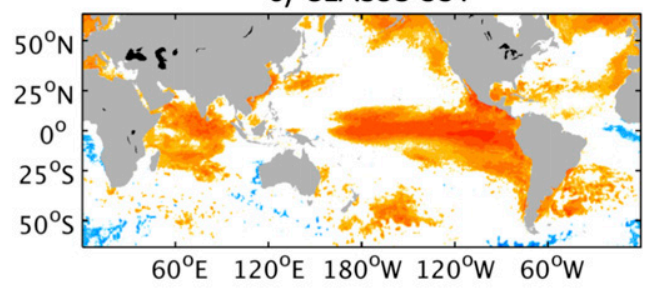

b) CLASS2 SST

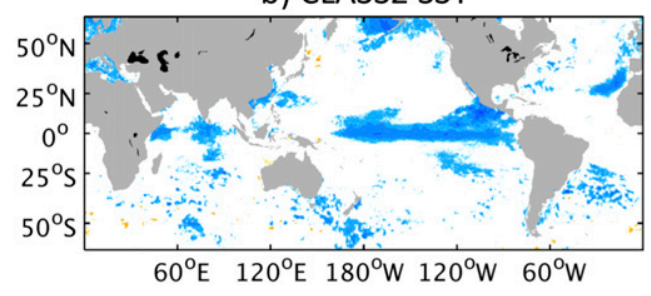

d) CLASS4 SST

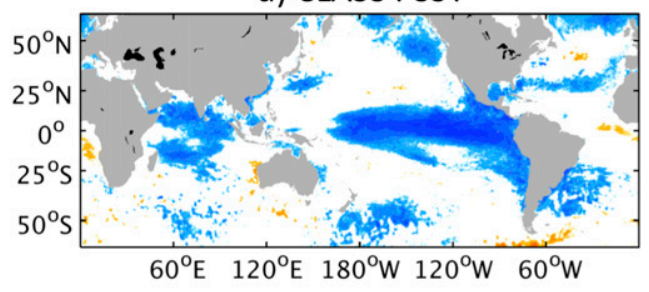

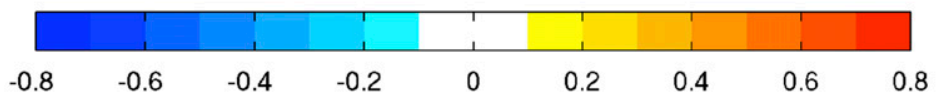

FIG. 9. Heterogeneous correlations between yearly regime occurrences in MERRA and October-March SSTs (shadings) over the 1982-2013 period. All correlations are significant at 5\% level using Monte Carlo simulations.

development of extratropical responses to tropical forcing after 2 weeks (Jin and Hoskins 1995; Lin et al. 2007); it is also comparable to the persistence times of regimes $2-4$, as well as those of retractions and latitudinal shifts of the
North Pacific jet exit region in winter (Jaffe et al. 2011; Griffin and Martin 2017). For the NAO-like regimes 2 and 4, this lag is also consistent with the time scale of the MJO's influence on the NAO (Cassou 2008; Lin et al. 2009; a) CLASS1

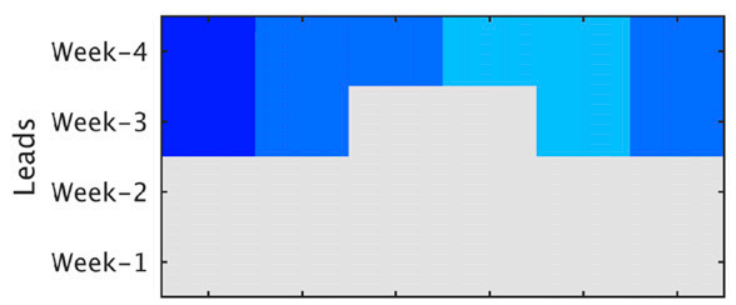

c) CLASS3

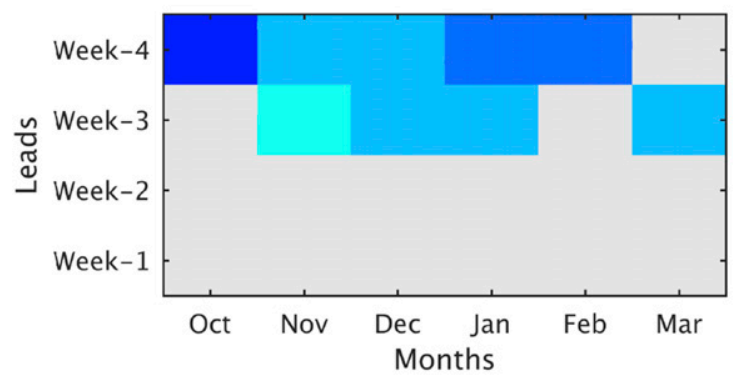

b) CLASS2

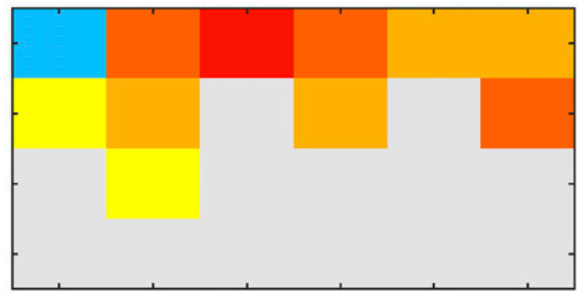

d) CLASS4

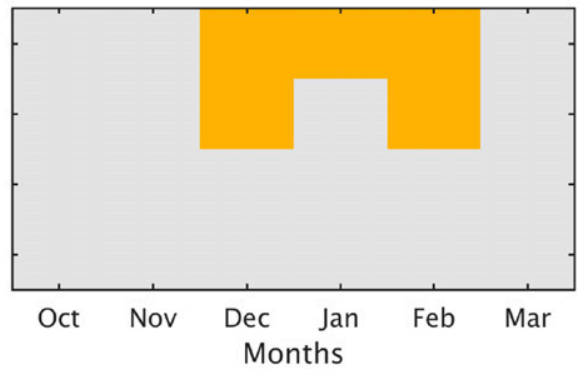

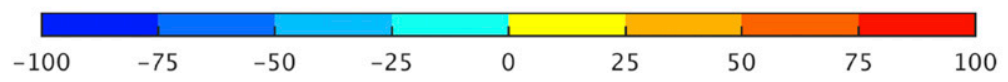

FIG. 10. Percentage differences in the number of days spent in each regime for ECMWF week-1 to week-4 reforecasts ( $y$ axis), compared to MERRA, per month of the October-March season during the 1995-2014 period. Significance is indicated by gray shadings for differences not significant at $5 \%$ level of significance using a Student's $t$ test. 
Lin and Brunet 2018). Regime 3 is associated with precipitation anomalies in the western United States (Fig. 5), consistent with the MJO-induced modulations of atmospheric rivers found in Zhang (2013). In terms of temperature, the increased prevalence of regimes 2-3 and 4, 10-15 days after MJO phases 6 and 3, respectively, agree with MJO-related warming over North America (Figs. 6b-d), which has been found to be predictable with substantial skill (Lin et al. 2009; Yao et al. 2011; Lin and Brunet 2018).

\section{c. Year-to-year variability and large-scale SSTs}

Yearly regime occurrences are shown as anomalies to the seasonal mean in Fig. 8 for MERRA and ECMWF week 1 over their respective 1982-2014 and 1995-2014 periods. Yearly modulations in the frequencies of each regime in ECMWF week-1 reforecasts are coherent with those in MERRA, as shown by significant correlations between both time series $(0.91,0.84,0.95$, and 0.89 for regimes $1-4$, respectively), and corroborates similar yearly proportions (not shown). Figure 8 could suggest upward and downward trends for regimes 3 and 2, respectively, consistent with those of the Pacific trough and Arctic high frequencies over the 1975-2000 period reported by Straus et al. (2007); however, these might just reflect internal climate variability over the small sampling period, as demonstrated for decadal variations of the NAO by Weisheimer et al. (2017).

Correlations between yearly counts of MERRA Z500 regime occurrences during the October-March season (with the long-term climatological mean removed; i.e., the time series in Fig. 8) and yearly October-March SST anomalies are shown in Fig. 9. The frequency of occurrences of regime 1 is related to warm conditions in the equatorial Pacific from the date line to eastern regions of the basin, with similar positive correlations in the midlatitudes (Fig. 9a), while opposite relationships are typical of regime 2 (Fig. 9b). Compared to regimes 1 and 2 , regimes 3 and 4 are characterized by stronger relationships in the tropical Pacific that extend along the west coast of North and South America, bearing similarities to the canonical ENSO pattern. Relationships with warm ENSO phases for regime 3 are consistent with maximum frequencies for some marked El Niño years in Fig. 8c (i.e., 1997-98, 2002-03, and 2009-10), while opposite relationships for regime 4 agree with minimum frequencies for the same years (Fig. 8d). Wet conditions over the western United States for regime 3 are consistent with $\mathrm{El}$ Niño teleconnection pattern in winter, when the TNH pattern (Barnston and Livezey 1987) prevails with northwest-southeast-tilted negative height anomalies over the North Pacific (Robertson and Ghil 1999) and more southerly storm tracks (Monteverdi

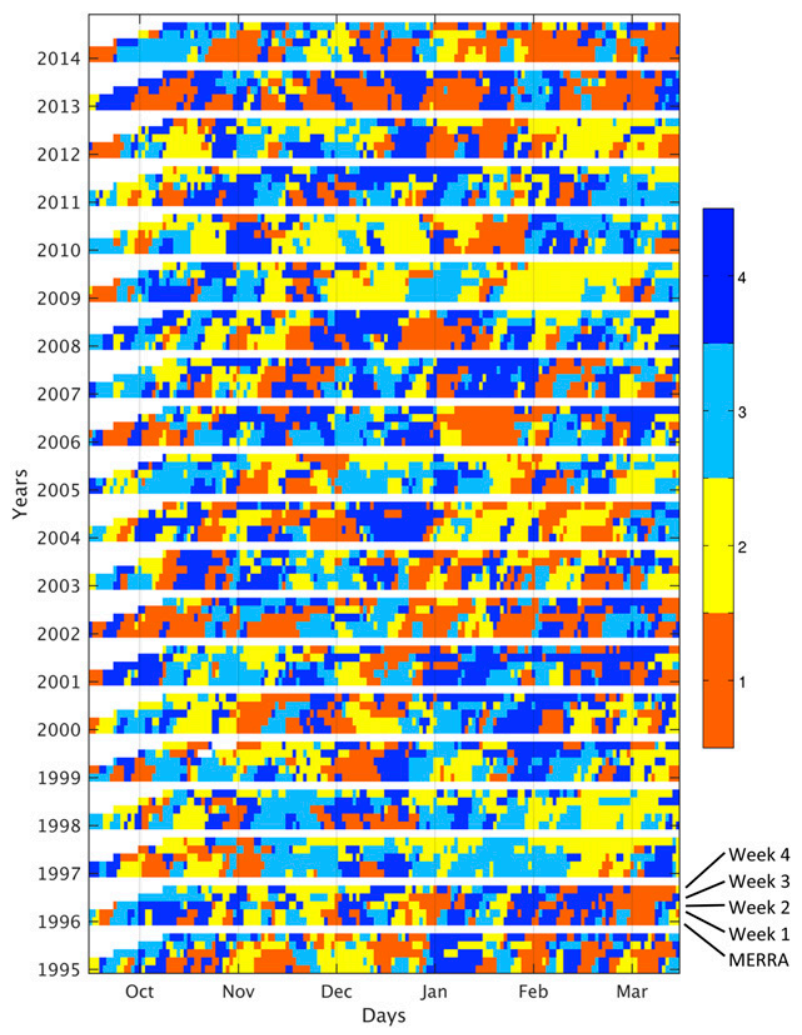

FIG. 11. Day-to-day classifiability in the October-March seasons during the 1995-2014 period when each day is projected onto MERRA 4-cluster partition obtained over the 1982-2014 period. For each year, the first line is the composite weekly sequence observed in MERRA for every ECMWF Monday start, while the lines above correspond to those forecast by ECMWF at week-1 to week-4 leads (i.e., over the periods $[d, d+6]$ to $[d+22, d+28]$ for a forecast issued on day $d$ ). Vertical alignment of the classification colors is indicative of a skillful forecast.

and Null 1998). Both regimes exhibit opposite ENSO-like anomalies in the tropical Pacific and same-sign relationships to SSTs in the Atlantic and Indian Oceans. Regime relationships to the tropical Pacific are consistent with potential associations with variability in the jet position over the North Atlantic and Pacific (Athanasiadis et al. 2010) and its linkages to mean surface conditions in the Pacific (Delcambre et al. 2013).

\section{Predictability from submonthly reforecasts}

The predictability of the circulation regimes presented in section 3 is here discussed using ECMWF ensemble mean reforecasts from week- 1 to week-4 leads. To allow a direct evaluation of forecast sequences against those observed in MERRA, the WRs computed from MERRA daily Z500 are used to classify each daily Z500 pattern from ECMWF ensemble mean 

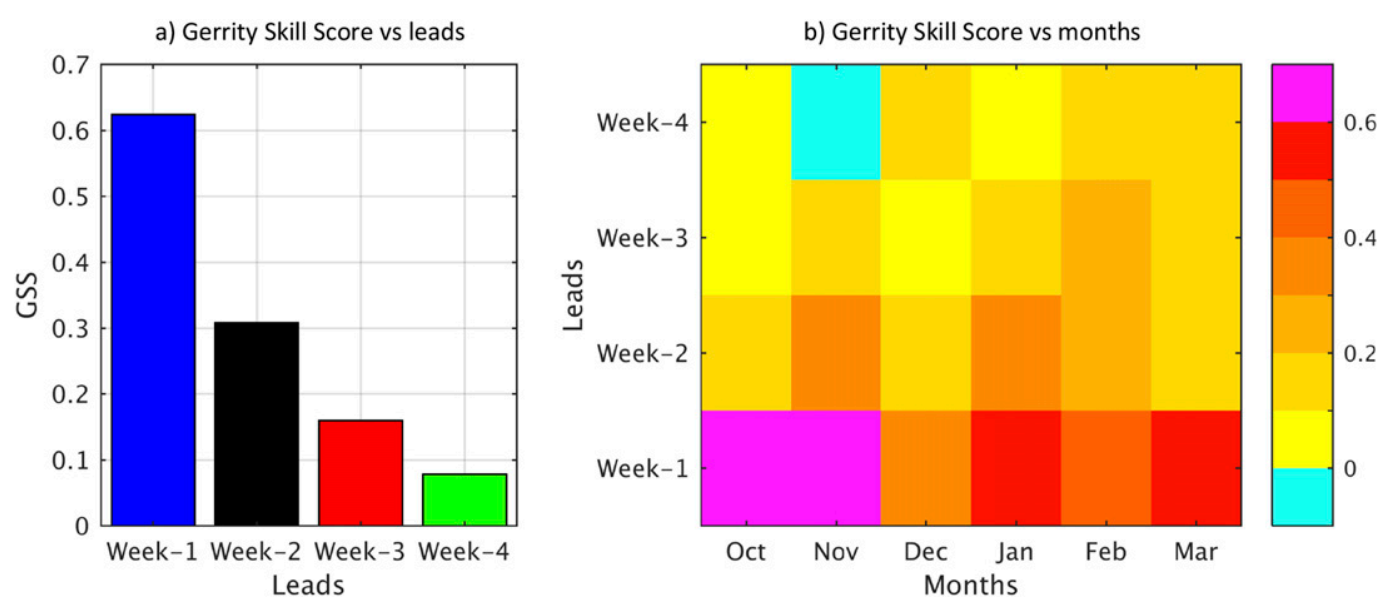

FIG. 12. Gerrity skill score (Gerrity 1992) for ECMWF week-1 to week-4 reforecasts averaged over (a) the 19952014 period and (b) for each month in October-March.

reforecasts as a single regime occurrence for which Euclidean distance is minimized. ECMWF ensemble mean reforecasts are chosen to take advantage of the 11-member ensemble and thus represent the best estimate of the model signal. The reproducibility of regime sequences is first investigated across lead times by examining how those observed are reproduced in week-1 to week-4 ECMWF ensemble mean reforecasts during the October-March season. The skill in forecasting these regimes (i.e., categorical forecasts) is investigated for all WRs using the multiple-category Gerrity skill score (Gerrity 1992). Forecast regime counts are then diagnosed with ACC and RMSE for weekly averages (weeks 1-4).

\section{a. Reproducibility versus lead time}

Differences in regime frequency between observation and reforecasts at week- 1 to week-4 leads are summarized by calendar month in Fig. 10. At week-1 and week-2 leads, regime counts are forecast with little bias from October to March (i.e., no significant differences on the first two lines of each panel), except regime 2 in November. From week 3, significant differences appear between observed and forecast monthly counts, with ECMWF reforecasts underestimating the number of days spent in regimes 1 and 3 from October to March, but overestimating those spent in regimes 2 and 4 during the whole October-March period and in DecemberFebruary, respectively. This could reflect the lesser predictability of intermediate-scale wave patterns (regimes 1 and 3) after 2 weeks, compared to larger-scale teleconnections, which are more stationary. These differences are enhanced with increasing lead and coincide with ECMWF overestimation of regime 2 occurrences at week-1 lead (Tables 1,2), suggesting model drift in regime 2 at longer leads.

Figure 11 shows regime sequences observed in MERRA and forecast by ECMWF ensemble mean at week-1 to week-4 leads (i.e., over the periods from $[d, d+6]$ to $[d+21, d+27]$ for a forecast issued on day d) for Monday starts in October-March from 1995 to 2014. At week-1 lead, the ECMWF regime sequence is very similar to MERRA, as indicated by an almost oneto-one correspondence between the first two lines for each year (i.e., success ratio around 0.8 for all regimes; not shown). At week 2 (third line), forecast sequences are close to those in MERRA, but skill is decreased from week 1 . From week 3, more differences appear between forecast and observation.

\section{b. Predictability of regime occurrences on a daily basis}

The multiple-category Gerrity skill scores in Fig. 12a display substantial skill for week-1 leads (above 0.6) but a sharp drop for week 2 (about 0.3 ) and lesser decreases toward week 4 (below 0.1), thus suggesting low skill in predicting regime occurrences on a daily basis after 2 weeks, consistent with the deterministic predictability limit (Ghil and Robertson 2002). The stratification of skill across month starts in Fig. 12b reflects low skill level after week 1 . At week-1 lead, it indicates highest skill in October-November but more skill in the second half of the season from week 2 .

\section{c. Skill in predicting regime counts}

The skill in predicting 7-day regime counts (i.e., the number of days in each regime) is diagnosed in Fig. 13 across lead time (up to 25 days) for 7-day sliding window 


\section{a) ACC}

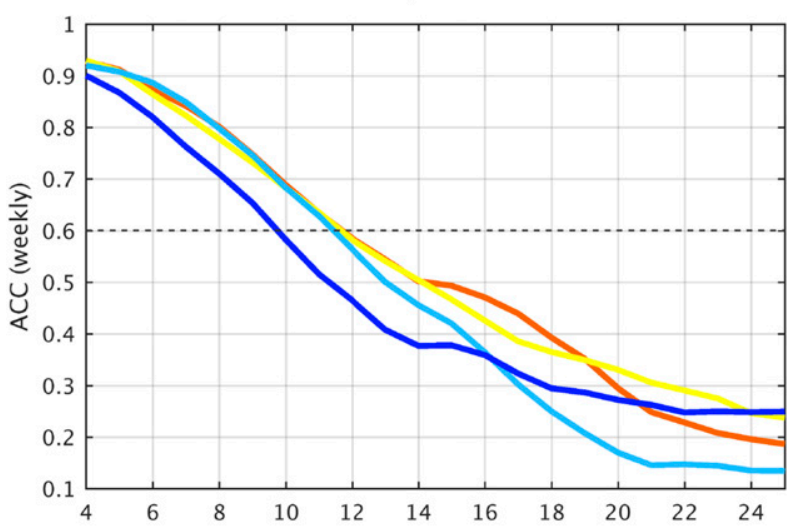

b) RMSE

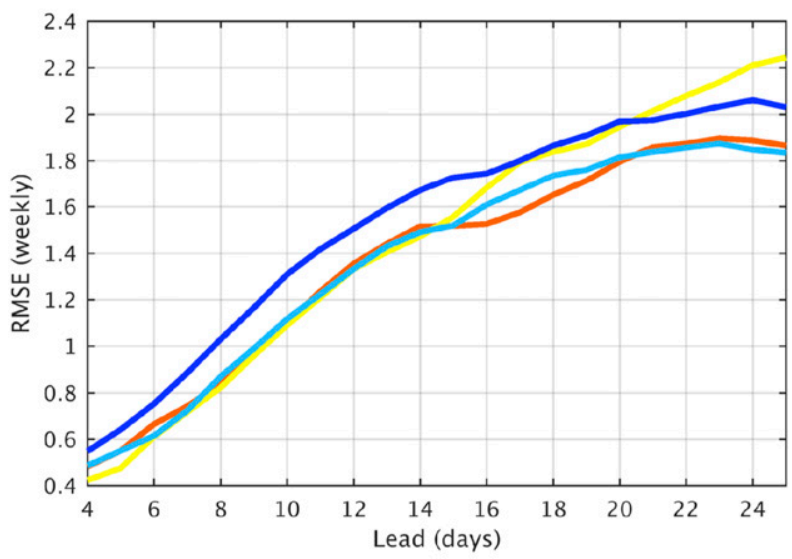

$=$ CLASS1 $=$ CLASS2 CLASS3 $=$ CLAS

FIG. 13. (a) ACC and (b) RMSE for ECMWF reforecasts as a function of lead (in days) for weekly targets centered on the calendar day (i.e., for the period [ $d-3, d+3]$ for a lead of $d$ days).

targets (i.e., for the period $[d-3, d+3]$ for a lead of $d$ days) and each regime separately. The ACC between 7-day counts forecast by ECMWF ensemble mean and observed from MERRA reanalyses is used here as a deterministic measure of skill and indicates predictability between 10 (regime 4 ) and 12 days (regimes 1 and 2), as shown by correlations above 0.6 in Fig. 13a, which is again comparable to the predictability of the mean jet position in the North Pacific (Griffin and Martin 2017). From 2 to 3 weeks' lead (i.e., for $d$ between 14 and 21 days), regimes 1 and 2 are associated with more skillful predictions (ACC around 0.3), compared to the other regimes, while beyond 3 weeks (i.e., $d>21$ ), regimes 2 and 4 are more skillful, but skill levels are rather limited (ACC about 0.25). RMSE is consistent with increasing errors in weekly counts with lead time for each regime (Fig. 13b) and also reflects ECMWF systematic bias (Tables 1,2) and overestimation of regime 2 occurrences with lead time (Fig. 10b), as shown by highest errors beyond 3 weeks' lead.

The stratification of skill by calendar month in Fig. 14 also indicates low skill (i.e., ACC < 0.6) after 11-14 days for all regimes, except for regime 1 in January and regime 2 in February, for which ACC is above 0.6 up to 17 days' lead. Regime 2 correlations have a local maximum (ACC > 0.4) in November at 20-24 days' lead, which might suggest opportunities for skillful predictions. Regimes 3 and 4 exhibit a similar bimodal skill behavior, as noticed for regime 2, with ACC peaks in December and March but with lower level of skill as measured by ACC $>0.6$ up to 13 and 14 days' lead, respectively. Higher skill in late winter, also emphasized at daily time scales (Fig. 12b), could be related to ENSO peak influence on western U.S. rainfall (Jong et al. 2016) and Arctic Oscillation (AO) controls on storm tracks and local spring onset (McAfee and Russell 2008). Biweekly ACC computed for weeks $2-3$ is improved, compared to the mean of weeks 2 and 3 (about 20\%; not shown); however, the value of higher skill for biweekly periods is unclear, since it mainly arises from higher skill during the first week of the 2-week period.

\section{Summary and conclusions}

This study aimed at documenting atmospheric circulation variability over North America from October to March using daily MERRA Z500 and submonthly ECMWF reforecasts. An EOF analysis is first performed on the data correlation matrix, and a dynamical clustering ( $k$-means) is applied to MERRA and ECMWF week-1 (days 1-7) ensemble mean daily Z500 anomalies (defined with respect to the mean seasonal cycle removed) over the Pacific-North American sector. Four weather regimes are identified (Figs. 1, 2, 4) with Z500 anomalies corresponding well with the Alaskan ridge (AR; regime 1), Arctic high ( $\mathrm{AH}$; regime 2), $\mathrm{Pa}-$ cific trough (PT; regime 3), and Arctic low (AL; regime 4) discussed in earlier weather-typing studies (Straus et al. 2007; Stan and Straus 2007). MERRA geopotential composites (Fig. 3) suggest relationships to Rossby wave train patterns with some baroclinicity for all regimes, except the $\mathrm{AH}$ regime (regime 2) more resembles the negative phase of the NAO, whose positive phase also bears some similarities to one of the wave train regimes (regime 4). The overall regime patterns also coincide well with primary modes of variability in the mean position of the jet over the North Atlantic and Pacific basins (Athanasiadis et al. 2010; Jaffe et al. 2011; Delcambre et al. 2013; Griffin and Martin 2017), further emphasizing influences from the North Pacific influence on the North Atlantic and the northern annular 
a) CLASS1

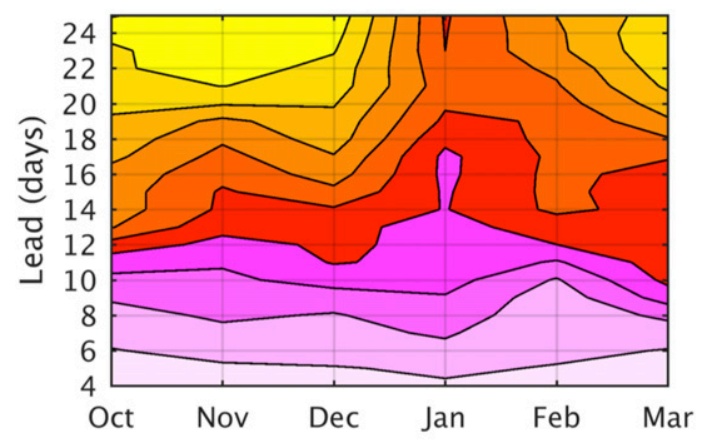

c) CLASS3

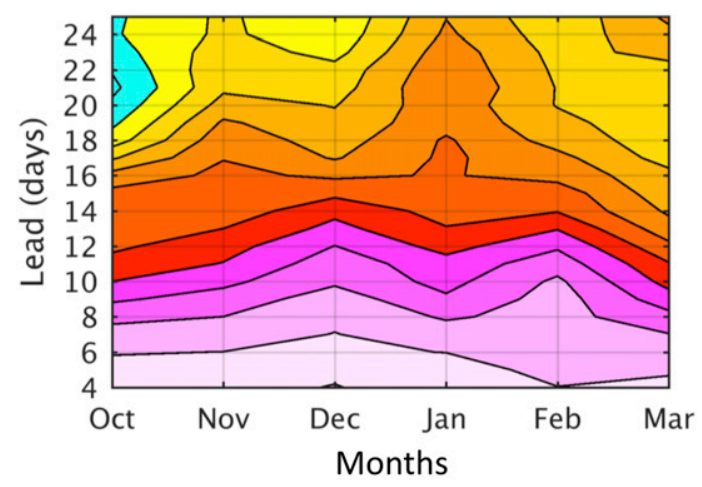

b) CLASS2

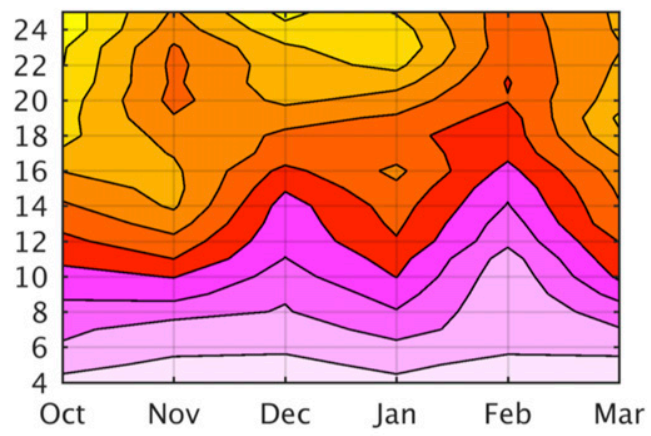

d) CLASS4

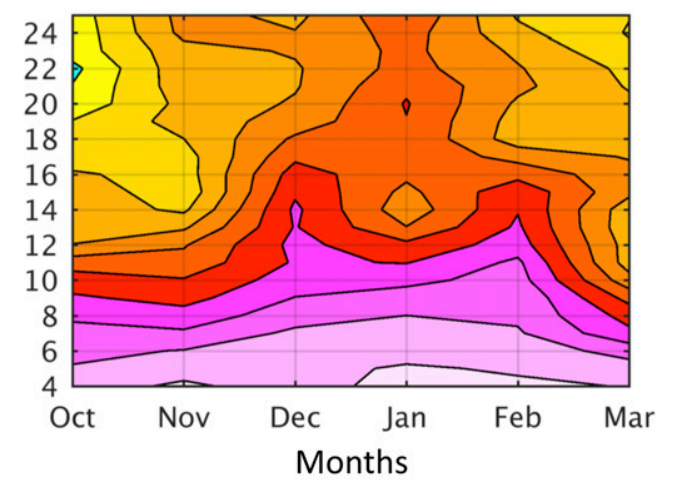

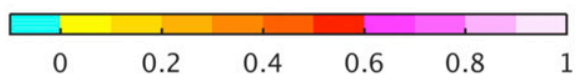

FIG. 14. ACC for ECMWF reforecasts as a function of lead (in days) and month start for each regime and weekly targets centered on the calendar day (i.e., for the period $[d-3, d+3]$ for a lead of $d$ days).

mode through Rossby wave propagation (Rivière and Drouard 2015; Michel and Rivière 2011); this is consistent with distinct relationships to rainfall identified for each regime across composites of MERRA and CPC Unified precipitation estimates (Fig. 5). For all regimes, Z500 patterns and associated rainfall anomalies are well reproduced in ECMWF week-1 ensemble mean reforecasts. Additional regime relationships to surface temperatures in MERRA and ECMWF (Fig. 6) suggest potentials for predictability of both North American winter rainfall and temperatures if regime evolutions and transitions can be predicted.

ECMWF overestimates the frequency of all regimes except one (regime 4; Tables 1,2), which might be related to phase differences between observed waves and those simulated by the model. All regimes but one (regime 1) are related to the MJO (Fig. 7) and are more frequent when MJO phases 6 (regimes 2 and 3) and 3 (regime 4) lead up to 2 weeks. This is consistent with rainfall and meridional ridge/trough anomalies for these regimes over the western United States and MJO-induced modulations of atmospheric rivers (Zhang 2013), but also with MJO-induced warming over North America during phases 2, 3, 6, and 7, for which there is substantial skill (Lin et al. 2009; Yao et al. 2011; Lin and Brunet 2018). Lagged MJO relationships are within the predictability range (about 10 days) of persisting retractions and latitudinal shifts of the North Pacific jet exit region in winter (Jaffe et al. 2011; Griffin and Martin 2017), and maxima for phases 3 and 6 are consistent with marked MJO dipole anomalies during these phases, when extratropical teleconnections are favored with likely occurrences of the NAO positive and negative phases, respectively (Lin et al. 2009, 2010; Lin and Brunet 2018). Agreeing with the downward trend in Arctic high frequencies noted by Straus et al. (2007), MERRA and ECMWF both suggest a decrease of regime 2 occurrences over 1995-2014 (Fig. 8), which could also reflect internal climate variability over the small sampling period (Weisheimer et al. 2017). At seasonal time scales, all regime frequencies are significantly correlated with SSTs in the Pacific with same-sign relationships to the Atlantic and Indian Oceans (Fig. 9). Relationships to tropical Pacific SSTs are consistent with regime 
associations with the jet position over the North Atlantic and Pacific (Athanasiadis et al. 2010), the jet position being itself linked to mean surface conditions in the Pacific (Delcambre et al. 2013). Regimes 3 and 4 display relationships bearing similarities to the canonical ENSO pattern, agreeing in terms of regime frequency during marked El Niño years (i.e., 1997-98, 2002-03, and 200910). These relationships are consistent with a prevalent TNH pattern (Barnston and Livezey 1987), northwestsoutheast-tilted negative height anomalies over the North Pacific (Robertson and Ghil 1999), and more southerly storm tracks (Monteverdi and Null 1998), translating into wet anomalies over the western United States during El Niño events similar to those of regime 3.

Daily Z500 patterns from ECMWF ensemble mean are next projected onto MERRA regimes and classified as a single regime occurrence for which Euclidean distance is minimized. In terms of monthly regime counts, the model systematic biases are magnified with increasing lead time (Fig. 10). On a daily basis, the skill of ECMWF reforecasts in reproducing regime occurrences observed in MERRA (Fig. 11) decreases with increasing lead and sharply drops from week 2 , as shown by multiple-category Gerrity skill scores (Fig. 12). Depending on the regime, weekly regime counts are skillfully predicted out to 10-12 days' lead in ECMWF reforecasts (Fig. 13) when assessed in terms of anomaly correlations (i.e., ACC > 0.6) with observed counts in MERRA. Regime 2 exhibits the most skillful predictions, up to 17 days' lead in February (Fig. 14), potentially related to ENSO peak influence on western U.S. rainfall (Jong et al. 2016) and AO controls on storm tracks and local spring onset (McAfee and Russell 2008).

Overall, this study proposes a convenient framework for model diagnostics allowing S2S predictability over the North American region with distinct relationships to rainfall and surface temperatures. The spatial structures of the observed circulation types, as well as their qualitative relationships with both rainfall and surface temperature patterns over the United States, are reproducible by stateof-the-art EPS submonthly reforecasts. However, the skill in reproducing observed daily regime sequences and weekly counts is limited after 2 weeks, agreeing with the predictability of weekly rainfall tercile probabilities from a multimodel ensemble of submonthly reforecasts over the region (Vigaud et al. 2017). Meanwhile, our results indicate skill relationships to the MJO, ENSO, and SSTs in the Atlantic and Indian Oceans that need to be further investigated to benefit regional prediction efforts.

Acknowledgments. The authors thank A. Barnston, F. Vitart, L. Ferranti, and M. Ghil for insightful discussions, but also the reviewers whose suggestions helped improve the manuscript substantially. The authors also acknowledge the financial support of the NOAA Next Generation Global Prediction System (NGGPS) Grant NA15NWS4680014, as well as the use of reforecasts available through the S2S database recently published under the WWRP/WCRP S2S project (http:// s2sprediction.net). Calculations were performed using IRI resources and the S2S subset archived in the IRI Data Library (IRIDL; http://iridl.ldeo.clumbia.edu). The IRIDL was also used to access all data analyzed in this study.

\section{REFERENCES}

Athanasiadis, P., J. Wallace, and J. Wettstein, 2010: Patterns of wintertime jet stream variability and their relation to the storm tracks. J. Atmos. Sci., 67, 1361-1381, https://doi.org/ 10.1175/2009JAS3270.1.

Baldwin, M., and T. Dunkerton, 2001: Stratospheric harbingers of anomalous weather regimes. Science, 294, 581-584, https:// doi.org/10.1126/science.1063315.

Barnston, A., and R. Livezey, 1987: Classification, seasonality and persistence of low-frequency atmospheric circulation patterns. Mon. Wea. Rev., 115, 1083-1126, https://doi.org/10.1175/15200493(1987)115<1083:CSAPOL $>2.0$. CO;2.

Becker, E., E. H. Berbery, and R. Higgins, 2011: Modulations of cold season U.S. daily precipitation by the Madden-Julian oscillation. J. Climate, 24, 5157-5166, https://doi.org/10.1175/ 2011JCLI4018.1.

Bjerknes, J., 1969: Atmospheric teleconnections from the equatorial Pacific. Mon. Wea. Rev., 97, 163-172, https://doi.org/ 10.1175/1520-0493(1969)097<0163:ATFTEP > 2.3.CO;2.

Blackmon, M., Y.-H. Lee, and J. Wallace, 1984: Horizontal structure of $500 \mathrm{mb}$ height fluctuations with long, intermediate and short time scales. J. Atmos. Sci., 41, 961-980, https://doi.org/ 10.1175/1520-0469(1984)041<0961:HSOMHF>2.0.CO;2.

Cassou, C., 2008: Intraseasonal interaction between the MaddenJulian oscillation and the North Atlantic Oscillation. Nature, 455, 523-527, https://doi.org/10.1038/nature07286.

Chen, P. X. M., and Coauthors, 2008: CPC unified gauge-based analysis of global daily precipitation. Western Pacific Geophysics Meeting, Cairns, Australia, Amer. Geophys. Union, 14 pp.

Chen, W., and H. van den Dool, 2003: Sensitivity of teleconnection patterns to the sign of their primary action center. Mon. Wea. Rev., 131, 2885-2899, https://doi.org/10.1175/15200493(2003) $131<2885$ :SOTPTT > 2.0.CO;2.

Delcambre, S., D. Lorenz, D. Vimont, and J. Martin, 2013: Diagnosing Northern Hemisphere jet portrayal in 17 CMIP3 Global Climate Models: Twentieth-century intermodel variability. J. Climate, 26, 4910-4929, https://doi.org/10.1175/ JCLI-D-12-00337.1.

DelSole, T., and M. Tippett, 2016: Forecast comparison based on random walks. Mon. Wea. Rev., 144, 615-626, https://doi.org/ 10.1175/MWR-D-15-0218.1.

Dunstone, N., D. Smith, A. Scaife, L. Hermanson, R. Eade, N. Robinson, M. Andrews, and J. Knight, 2016: Skilful predictions of the winter North Atlantic Oscillation one year ahead. Nat. Geosci., 9, 809-814, https://doi.org/10.1038/ngeo2824.

Eade, R., D. Smith, A. Scaife, E. Wallace, N. Dunstone, L. Hermanson, and N. Robinson, 2014: Do seasonal-to-decadal climate predictions underestimate the predictability of the real world? Geophys. Res. Lett., 41, 5620-5628, https://doi.org/10.1002/2014GL061146. 
Ferranti, L., S. Corti, and M. Janousek, 2015: Flow-dependent verification of the ECMWF ensemble over the Euro-Atlantic sector. Quart. J. Roy. Meteor. Soc., 141, 916-924, https:// doi.org/10.1002/qj.2411.

Gerrity, J., 1992: A note on Gandin and Murphy's equitable skill score. Mon. Wea. Rev., 120, 2709-2712, https://doi.org/10.1175/ 1520-0493(1992)120<2709:ANOGAM>2.0.CO;2.

Ghil, M., and A. Robertson, 2002: "Waves" vs. "particles" in the atmosphere's phase space: A pathway to long-range forecasting? Proc. Nat. Acad. Sci., 99, 2493-2500, https://doi.org/ 10.1073/pnas.012580899.

Griffin, K., and J. Martin, 2017: Synoptic features associated with temporally coherent modes of variability of the North Pacific jet stream. J. Climate, 30, 39-54, https://doi.org/10.1175/JCLID-15-0833.1.

Halpert, M., and C. Ropelewski, 1992: Surface temperature patterns associated with the southern oscillation. J. Climate, $\mathbf{5}$, 577-593, https://doi.org/10.1175/1520-0442(1992)005<0577: STPAWT $>2.0 . \mathrm{CO} ; 2$.

Higgins, R., and W. Shi, 2000: Dominant factors responsible for interannual variability of the summer monsoon in the southwestern United States. J. Climate, 13, 759-776, https://doi.org/ 10.1175/1520-0442(2000)013<0759:DFRFIV>2.0.CO;2.

Holland, M. M., D. A. Bailey, and S. Vavrus, 2011: Inherent sea ice predictability in the rapidly changing Arctic environment of the Community Climate System Model, version 3. Climate Dyn., 36, 1239-1253, https://doi.org/10.1007/s00382-010-0792-4.

Hoskins, B., and D. Karoly, 1981: The steady linear response of a spherical atmosphere to thermal and orographic forcing. J. Atmos. Sci., 38, 1179-1196, https://doi.org/10.1175/15200469(1981)038<1179:TSLROA > 2.0.CO;2.

— longitudinally varying flow. J. Atmos. Sci., 50, 1661-1671, https:// doi.org/10.1175/1520-0469(1993)050<1661:RWPOAR > 2.0.CO;2.

Jaffe, S. C., J. Martin, D. Vimont, and D. Lorenz, 2011: A synoptic climatology of episodic, subseasonal retractions of the Pacific jet. J. Climate, 24, 2846-2860, https://doi.org/10.1175/2010JCLI3995.1.

Jin, F., and B. Hoskins, 1995: The direct response to tropical heating in a baroclinic atmosphere. J. Atmos. Sci., 52, 307-319, https:// doi.org/10.1175/1520-0469(1995)052<0307:TDRTTH>2.0.CO;2.

Jong, B.-T., M. Ting, and R. Seager, 2016: El Niño's impact on California precipitation: Seasonality, regionality, and El Niño intensity. Environ. Res. Lett., 11, 054021, https://doi.org/ 10.1088/1748-9326/11/5/054021.

Karoly, D., 1983: Rossby wave propagation in a barotropic atmosphere. Dyn. Atmos. Oceans, 7, 111-125, https://doi.org/10.1016/ 0377-0265(83)90013-1.

Kimoto, M., and M. Ghil, 1993a: Multiple flow regimes in the Northern Hemisphere winter. Part I: Methodology and hemispheric regimes. J. Atmos. Sci., 50, 2625-2644, https:// doi.org/10.1175/1520-0469(1993)050<2625:MFRITN $>2.0 . C O ; 2$.

_ Hemisphere winter. Part II: Sectorial regimes and preferred transitions. J. Atmos. Sci., 50, 2645-2673, https://doi.org/ 10.1175/1520-0469(1993)050<2645:MFRITN > 2.0.CO;2.

Kolstad, E., T. Bracegirdle, and I. Seierstad, 2009: Marine cold-air outbreaks in the North Atlantic: Temporal distribution and associations with large-scale atmospheric circulation. Climate Dyn., 33, 187-197, https://doi.org/10.1007/s00382-008-0431-5.

Koster, R., and Coauthors, 2010: Contribution of land surface initialization to subseasonal forecast skill: First results from a multi-model experiment. Geophys. Res. Lett., 37, L02402, https://doi.org/10.1029/2009GL041677.
Liebmann, B., and C. Smith, 1996: Description of a complete (interpolated) outgoing longwave radiation dataset. Bull. Amer. Meteor. Soc., 77, 1275-1277, https://doi.org/10.1175/ 1520-0477-77.6.1274.

Lin, H., and G. Brunet, 2009: The influence of the Madden-Julian oscillation on Canadian wintertime surface air temperature. Mon. Wea. Rev., 137, 2250-2262, https://doi.org/10.1175/ 2009MWR2831.1.

— teau snow cover to seasonal prediction of North American winter temperature. J. Climate, 24, 2801-2813, https://doi.org/ 10.1175/2010JCLI3889.1.

_ Nonlinearity and sensitivity to the initial state. J. Atmos. Sci., 75, 219-234, https://doi.org/10.1175/JAS-D-17-0189.1.

_, J. Derome, and G. Brunet, 2005: Tropical Pacific link to the two dominant patterns of atmospheric variability. Geophys. Res. Lett., 32, L03801, https://doi.org/10.1029/2004GL021495.

$\_, \ldots$, and — 2007: The nonlinear transient atmospheric response to tropical forcing. J. Climate, 20, 5642-5665, https:// doi.org/10.1175/2007JCLI1383.1.

_ - G. Brunet, and J. Derome, 2009: An observed connection between the North Atlantic Oscillation and the MaddenJulian oscillation. J. Climate, 22, 364-380, https://doi.org/ 10.1175/2008JCLI2515.1.

_,- , and R. Mo, 2010: Impact of the Madden-Julian oscillation on wintertime precipitation in Canada. Mon. Wea. Rev., 138, 3822-3839, https://doi.org/10.1175/2010MWR3363.1.

Madonna, E., C. Li, C. Grams, and T. Woollings, 2017: The link between eddy-driven jet variability and weather regimes in the North Atlantic-European sector. Quart. J. Roy. Meteor. Soc., 143, 2960-2972, https://doi.org/10.1002/qj.3155.

McAfee, S., and J. Russell, 2008: Northern annular mode impact on spring climate in the western United States. Geophys. Res. Lett., 35, L17701, https://doi.org/10.1029/2008GL034828.

Michel, C., and G. Rivière, 2011: The link between Rossby wave breakings and weather regime transitions. J. Atmos. Sci., 68 , 1730-1748, https://doi.org/10.1175/2011JAS3635.1.

Michelangeli, P., R. Vautard, and B. Legras, 1995: Weather regimes: Recurrence and quasi stationarity. J. Atmos. Sci., 52, 1237-1256, https://doi.org/10.1175/1520-0469(1995)052<1237: WRRAQS $>2.0 . \mathrm{CO} ; 2$.

Monteverdi, J., and J. Null, 1998: A balanced view of the impact of the $1997 / 98$ El Niño on Californian precipitation. Weather, $\mathbf{5 3}$ 310-313, https://doi.org/10.1002/j.1477-8696.1998.tb06406.x.

Moron, V., and G. Plaut, 2003: The impact of El Niño-Southern Oscillation upon weather regimes over Europe and the North Atlantic during boreal winter. Int. J. Climatol., 23, 363-379, https://doi.org/10.1002/joc.890.

Neena, J. M., J. Y. Lee, D. Waliser, B. Wang, and X. Jiang, 2014: Predictability of the Madden-Julian oscillation in the Intraseasonal Variability Hindcast Experiment (ISVHE). J. Climate, 27, 4531-4543, https://doi.org/10.1175/JCLI-D-13-00624.1.

Papritz, L., and C. Grams, 2018: Linking low-frequency large-scale circulation patterns to cold air outbreak formation in the northeastern North Atlantic. Geophys. Res. Lett., 45, 2542 2553, https://doi.org/10.1002/2017GL076921.

Reynolds, R. W., T. M. Smith, C. Liu, D. Chelton, K. Casey, and M. Schlax, 2007: Daily high-resolution-blended analyses for sea surface temperature. J. Climate, 20, 5473-5496, https:// doi.org/10.1175/2007JCLI1824.1.

Riddle, E., M. Stoner, N. Johnson, M. L'Heureux, D. Collins, and S. Feldstein, 2013: The impact of the MJO on clusters of 
wintertime circulation anomalies over the North American region. Climate Dyn., 40, 1749-1766, https://doi.org/10.1007/ s00382-012-1493-y.

Rivière, G., and M. Drouard, 2015: Dynamics of the northern annular mode at weekly time scales. J. Atmos. Sci., 72, 45694590, https://doi.org/10.1175/JAS-D-15-0069.1.

Robertson, A., and W. Metz, 1989: Three-dimensional linear instability of persistent anomalous large-scale flows. J. Atmos. Sci., 46, 2783-2801, https://doi.org/10.1175/1520-0469(1989)046<2783: TDLIOP $>2.0 . \mathrm{CO} ; 2$.

, and M. Ghil, 1999: Large-scale weather regimes and local climate over the western United States. J. Climate, 12, 17961813, https://doi.org/10.1175/1520-0442(1999)012<1796: LSWRAL $>2.0 . \mathrm{CO} ; 2$.

_ , Y. Kushnir, U. Lall, and J. Nakamura, 2015: Weather and climatic drivers of extreme flooding events over the Midwest of the United States. Extreme Events: Observations, Modeling and Economics, Geophys. Monogr., Vol. 214, Amer. Geophys. Union, 113-124, https://doi.org/10.1002/9781119157052.ch9.

Ropelewski, C., and M. Halpert, 1987: Global and regional scale precipitation patterns associated with the El Niño/Southern Oscillation. Mon. Wea. Rev., 115, 1606-1626, https://doi.org/ 10.1175/1520-0493(1987)115<1606:GARSPP>2.0.CO;2.

Scaife, A., and J. Knight, 2008: Ensemble simulations of the cold European winter of 2005-2006. Quart. J. Roy. Meteor. Soc., 134, 1647-1659, https://doi.org/10.1002/qj.312.

, and Coauthors, 2014: Skillful long-range prediction of European and North American winters. Geophys. Res. Lett., 41, 2514-2519, https://doi.org/10.1002/2014GL059637.

Stan, C., and D. Straus, 2007: Is blocking a circulation regime? Mon. Wea. Rev., 135, 2406-2413, https://doi.org/10.1175/ MWR3410.1.

Straus, D., and F. Molteni, 2004: Circulation regimes and SST forcing: Results from large GCM ensembles. J. Climate, 17, 1641-1656, https://doi.org/10.1175/1520-0442(2004)017<1641: CRASFR $>2.0 . \mathrm{CO} ; 2$

_, S. Corti, and F. Molteni, 2007: Circulation regimes: Chaotic variability versus SST-forced predictability. J. Climate, 20, 2251-2272, https://doi.org/10.1175/JCLI4070.1.

van den Dool, V., S. Saha, and A. Johansson, 2000: Empirical orthogonal teleconnections. J. Climate, 13, 1421-1435, https:// doi.org/10.1175/1520-0442(2000)013<1421:EOT>2.0.CO;2.

Vautard, R., 1990: Multiple weather regimes over the North Atlantic: Analysis of precursors and successors. Mon. Wea. Rev., 118, 2056-2081, https://doi.org/10.1175/1520-0493(1990)118<2056: MWROTN $>2.0 . \mathrm{CO} ; 2$.

Vigaud, N., and A. Robertson, 2017: Convection regimes and tropical-midlatitude interactions over the Intra-American Seas from May to November. Int. J. Climatol., 37, 987-1000, https://doi.org/10.1002/joc.5051.

_ B. Pohl, and J. Crétat, 2012: Tropical-temperate interactions over southern Africa simulated by a regional climate model.
Climate Dyn., 39, 2895-2916, https://doi.org/10.1007/s00382012-1314-3.

— A. Robertson, and M. Tippett, 2017: Multimodel ensembling of subseasonal precipitation forecasts over North America. Mon. Wea. Rev., 145, 3913-3928, https://doi.org/10.1175/ MWR-D-17-0092.1.

Vitart, F., 2014: Evolution of ECMWF sub-seasonal forecast skill scores. Quart. J. Roy. Meteor. Soc., 140, 1889-1899, https:// doi.org/10.1002/qj.2256.

— , and Coauthors, 2017: The Subseasonal to Seasonal (S2S) Prediction project database. Bull. Amer. Meteor. Soc., 98, $163-$ 173, https://doi.org/10.1175/BAMS-D-16-0017.1.

Waliser, D. E., 2011: Predictability and forecasting. Intraseasonal Variability of the Atmosphere-Ocean Climate System, W. Lau and D. Waliser, Eds., Springer, 389-423, https://doi.org/ 10.1007/3-540-27250-X_12.

, K. M. Lau, W. Stern, and C. Jones, 2003: Potential predictability of the Madden-Julian oscillation. Bull. Amer. Meteor. Soc., 84, 33-50, https://doi.org/10.1175/BAMS-84-1-33.

Wallace, J., and D. S. Gutzler, 1981: Teleconnections in the geopotential height field during the Northern Hemisphere winter. Mon. Wea. Rev., 109, 784-812, https://doi.org/10.1175/15200493(1981)109<0784:TITGHF $>2.0$. CO;2.

Weisheimer, A., N. Schaller, C. O'Reilly, D. A. MacLeod, and T. Palmer, 2017: Atmospheric seasonal forecasts of the twentieth century: Multi-decadal variability in predictive skill of the winter North Atlantic Oscillation (NAO) and their potential value for extreme event attribution. Quart. J. Roy. Meteor. Soc., 143, 917-926, https://doi.org/10.1002/qj.2976.

Woollings, T., A. Hannachi, and B. Hoskins, 2010: Variability of the North Atlantic eddy-driven jet stream. Quart. J. Roy. Meteor. Soc., 136, 856-868, https://doi.org/10.1002/qj.625.

World Meteorological Organization, 2013: Sub-seasonal to Seasonal Prediction: Research implementation plan. WMO Rep., 71 pp., http://s2sprediction.net/file/documents_reports/S2S_ Implem_plan_en.pdf.

Yao, W., H. Lin, and J. Derome, 2011: Submonthly forecasting of winter surface air temperature in North America based on organized tropical convection. Atmos.-Ocean, 49, 51-60, https://doi.org/10.1080/07055900.2011.556882.

Yoo, C., and S.-W. Son, 2016: Modulation of the boreal wintertime Madden-Julian oscillation by the stratospheric quasi-biennial oscillation. Geophys. Res. Lett., 43, 1392-1398, https://doi.org/ 10.1002/2016GL067762.

Zhang, C., 2013: Madden-Julian oscillation: Bridging weather and climate. Bull. Amer. Meteor. Soc., 94, 1849-1870, https:// doi.org/10.1175/BAMS-D-12-00026.1.

Zhou, S., M. L'Heureux, S. Weaver, and A. Kumar, 2012: A composite study of the MJO influence on the surface air temperature and precipitation over the continental United States. Climate Dyn., 38, 1459-1471, https://doi.org/10.1007/ s00382-011-1001-9. 